\title{
Speculations About Early Syntax: The Production of Wh-questions by Normally Developing French Children and French Children with SLI*
}

\section{Cornelia Hamann}

University of Oldenburg. Department of English

Ammerländer Heerstrasse 114-118. 26129 Oldenburg. Germany

Cornelia.Hamann@uni-oldenburg.de

\section{Abstract}

This paper examines the spontaneous (and elicited) production of questions in 3 typically developing French children $(1 ; 8-2 ; 10)$ and 11 French children with SLI $(3 ; 10-9 ; 1)$. French has three types of constituent questions (Wh-in-situ, fronted Wh without inversion, fronted Wh with inversion) graded in syntactic complexity, allowing detailed investigation of syntactic competence.

The results show that both groups of children greatly prefer Wh-in-situ over fronted Wh and avoid inversion. Infinitives are extremely rare in all questions, whereas null subjects are rare in fronted Wh-questions but occur in in-situ questions in typically developing children. SLI children do not produce infinitives in Wh-questions, but allow null subjects in all question types. The elicitation experiment confirmed these trends, though the SLI children had significantly more difficulties with movement than the normal children.

A tentative account uses the truncation approach and the assumption that young children avoid movement by deriving in-situ questions with a Q-element in the head position of an Interrogative Phrase entering into an Agree relation with the element left in-situ. SLI children might extend this economic analysis to all Wh-questions.

Key words: French questions, fronted Wh, Wh-in-situ, syntactic complexity, infinitives, null subjects, movement, economic, typically developing children, SLI children.

\section{Table of Contents}

\section{Introduction}

2. Previous results and theoretical approaches

3. Method

4. Results for normally developing children
5. Results for French children with SLI

6. Confirming and extending the results for SLI children in elicitation experiments

\section{Discussion and Conclusion}

References

* Acknowledgements: I thank all the children participating in the study and the parents who made the recordings or welcomed the investigators in their homes. Special thanks go to Lara Baranzini, Stéphanie Cronel-Ohayon and Lucienne Rasetti for making their data available and helping with the reanalysis. My thanks also go to Luigi Rizzi, Ur Shlonsky, Ken Wexler and two anonymous reviewers for their comments and theoretical suggestions. In addition, I would like to thank all the colleagues from the Interfaculty Project in Geneva for their help in data collection, processing and analysis. I take sole responsibility, however, for the conclusions I draw and the errors I made. 


\section{Introduction}

\subsection{Aims and structure of the paper}

The aim of this paper is twofold. First, I want to confirm and extend the data on question formation in early French. Second, I intend to adapt and extend the analyses of early syntax discussed in the literature in order to account for the findings in a way consistent with current assumptions about economy constraints in child language. I therefore investigate the different constructions on the basis of more extensive corpora for typically developing children in order to determine possible preferences for certain question constructions and the phenomena occurring in the different question types. I also present data on question production in the spontaneous speech of 11 French children with SLI which corroborates that questions are indeed an area of particular difficulty. These findings lead to an analysis of the grammar of early French questions which uses and extends current hypotheses about child grammars.

Considerations about the role of economy in child language and an introduction into French question patterns are given in 1.2. Previous results on typically developing children and children with SLI are discussed in section 2.1, and proposals about early and impaired grammars will be presented in section 2.2. The participants and the method of data taking for spontaneous speech and in an elicitation experiment are discussed in section 3. Section 4 deals with the question patterns found in the spontaneous speech of typically developing children, and section 5 discusses language impaired children. In section 6 the spontaneous data are complemented with the results from an elicitation experiment, and section 7 sketches an economy-driven child grammar.

\subsection{Economy, French question types, acquisition and language impairment}

In the recent discussion about the nature of early and impaired grammars it has been suggested that such grammars are characterized by the exploitation and perhaps overextension of economy principles as known for adult grammar (see Chomsky (1995)). If children have limited processing capacities or limited working memories (Bloom 1990), then it is plausible to propose that they use certain grammatical options that alleviate processing load because they are simpler than others in derivation or representation or both. This guiding idea has lead to several recent proposals.

Newer formulations of the Truncation Hypothesis explicitly spell out an economy principle as a constraint on child grammars which assumes that children use the minimal structure that can accommodate the overt material and in doing so may override other requirements of the grammar, see Rizzi (2000:288). Rizzi (2000) does not specify how such a minimal structure could be defined, he refers the reader to previous literature such as Safir (1992), Cardinaletti and Starke (1994), Chomsky (1995) and others. His formulation, which will be quoted in full in section 2.3.2., allows for truncation of structural positions and for omission of elements. Though Rizzi does not specifically address the problem 
of derivational economy, this approach invites speculation about economy constraints and their relation to processing limitations in child language (see Rizzi 2000:278).

Focusing on derivational economy and pursuing similar ideas, Jakubowicz and colleagues (Jakubowicz and Nash (2001), Jakubowicz (2004)) have formulated a general hypothesis claiming that for typically developing children and for children with Specific Language Impairment (SLI) «less complex derivations are input convergent (i.e. correctly spelled out and pronounced at the interfaces) before more complex ones» (Jakubowicz 2005). They explicitly define a complexity metric on derivations concerning the basic operation Merge (external and internal). ${ }^{1}$ It basically states that a movement chain with $\mathrm{n}$ links is less complex than a chain with $(\mathrm{n}+1)$ links. In addition, a derivation requiring $\mathrm{n}$ chains is less complex than a derivation using $(n+1)$ chains. Counting complexity in numbers and links of chains is not new. Equally old is the idea that covert movement is less costly than overt movement. This can be recast in terms of Merge and Agree such that external Merge after Spell-out and Agree are to be preferred over internal Merge, an assumption which also plays a role in Jakubowicz (2004)'s account of computational complexity.

Stating that children tend to choose the less complex variant of two possible derivations - in the sense of involving less structure or in the sense of less complex chains or a combination of both - does not imply that children cannot build movement chains or produce finite verb forms. If there is morphological (or interpretational) material to be accommodated, they will observe well-formedness constraints, i.e. checking of the relevant features. This means in particular that if the numeration contains a finite verb form, then the verb will be raised in French child language, and that VP-internal subjects will be raised out of the VP. ${ }^{2}$ However, the same child may opt for a non-finite construction and a VP-internal subject (Friedemann (1992), (2000)) using less structure and no movement in the next utterance. The preponderance of such structures in the early phases in the acquisition of some languages (Dutch, see Wijnen (1997)) may be a hint that here also children aim for economy.

Structures that allow a true choice in the sense that there are two different derivations with (roughly) the same interpretation are rare, however. It is in this context that French question formation can be considered a test laboratory because French children hear and can choose different types of constituent questions (Whquestions) which can be ordered on a scale of syntactic complexity. The examples (1a-d) show this scale. It ranges from an in-situ question, (1a), via the colloquial-

1. Merging an element $\mathrm{n}$ times (externally or internally) is considered less complex than merging an element $(n+1)$ times. Moreover, internal merge of $n$ elements is considered less complex than internal merge of $(n+1)$ elements. See also Clark and Roberts (1993) for a similar metric and Chomsky (1995) on some necessary extensions of this simple notion.

2. Another kind of economy might involve the number of elements in numerations, as one reviewer points out. It is indeed possible that a different numeration is chosen which leads to a simpler derivation - as I suggest for the initial analysis of in-situ by children. See section 7 for more details. 
ly frequent (1b) to the standard formulation of questions in (1c) and (1d). (1a) has the surface form of a declarative sentence and is marked as a question by the insertion of a Wh-word in the position of the questioned constituent. This type is therefore called an in-situ question. There is no overt movement of the Wh-word and no subject verb inversion. (1b) shows a fronted Wh-word but no subject-verb inversion. Finally, in (1c) and (1d) not only the Wh-word has been fronted but the verb and the subject undergo inversion. We thus have a question type involving no movement, ${ }^{3}$ a question type with movement of the Wh-word only and a question type involving two movement chains, the Wh-chain and the verbal chain, offering the scale of complexity mentioned before. I will leave the discussion at this intuitive level here and refer the reader to Jakubowicz (2004) for a technical demonstration that in-situ questions are less complex than fronted Wh-questions without inversion and that the latter are less complex than inverted, fronted Wh-questions.
a. Il va où?
he goes where
'where does he go?'

b. Où il va?

where he goes

'where does he go?'

c. Où va- t-il?

where goes-t-he?

'where does he go?'

d. Où va la maman?

where goes the mommy

'where does mommy go?'

f. Où est-ce qu' il va? periphrastic

where is it that he goes

'where does he go?'

in-situ, colloquial French

fronted Wh without inversion, colloquial French

fronted Wh with inversion of a clitic subject

fronted Wh with inversion of a lexical subject

Some question elements (comment ('how'), où ('where'), quand ('when')) can occur in all of these constructions, others are structurally constrained. A reasonpourquoi ('why') can only be used in a fronted Wh-question, though it can be found in-situ when it introduces a purpose-question. ${ }^{4}$ In the French spoken in France and

3. To be precise, the Wh-word has not left its base position and the verb has not undergone any movement in addition to that necessary in declaratives.

4. One of the anonymous reviewers reports finding many in-situ pourquoi ('why') constructions with a simple web-search. When a similar web-search was started and the occurrences of pourquoi were analyzed, it turned out that they were all purpose uses of pourquoi ('what for'). 
Switzerland, quoi ('what') is constrained to the root and cannot be fronted. This seems to be different in Canadian French.

For completeness and because it becomes relevant when discussing the children with SLI, the frequent periphrastic question construction containing est-ce que ('is it that') is listed here, see (1f). This construction is compatible with practically all question words, and is particularly frequent for object questions. Object questions thus exist in the colloquial in-situ construction (2a), in the frequent periphrastic qu'est-ce que ('what is it that') (2b) and in the elevated style (2c). Estce que ('is it that') and qu'est-ce que ('what is it that') can be analyzed as overt complex Q-morphemes, the chunks ESK and KESK, respectively, so that periphrastic object questions are fronted Wh-questions without inversion. ${ }^{5}$
a. $\mathrm{Tu}$ fais quoi?
in-situ
you do what
'what are you doing?'

b. Qu' est-ce que tu fais? what is it that you do?

'what are you doing?'

c. Que fais-tu?

fronted Wh-question with inversion

what do you

'what are you doing?'

For yes-no questions a corresponding scale of complexity can be established with the three possibilities shown in (3a), (3b) and (3c). (3a) is the simplest type and uses essentially a declarative word order on which question force is marked by intonation only which might serve as Question-marker at LF. In the common periphrastic type, (3b), ESK can again be analyzed as a chunk, a question marker, so that there is no inversion. In the simplest analysis, this question marker has been merged as overt material to the declarative so that this form is more complex than (3a) on the Spell-out level. Finally, type (3c) shows the use of inversion as a marker of interrogative force. If (external) merge is less complex than internal merge, then $(3 \mathrm{c})$ is the most complex of these three forms.

5. See Cheng and Rooryck (2000) and the references cited there as well as Hulk and Zuckermann (2000). The main argument is that est-ce que occurs in yes-no questions and Wh-questions and functions as a questions marker in both types - just as intonation functions as the question marker in intonational yes-no questions and also plays a role in in-situ questions. Hulk and Zuckermann (2000) then extend such an analysis also to qu' est-ce que, KESK. 
a. Il a un chapeau?

he has a hat? 'has he a hat?/does he have a hat?'

b. Est-ce qu' il a un chapeau? is it that he has a hat?

'has he a hat?/does he have a hat?'

c. A- t-il un chapeau? has-t-he a hat 'has he a hat?/does he have a hat?' intonational question 6

periphrastic

subject-verb inversion

It has been argued that French in-situ questions have a special intonation and are semantically different from fronted Wh-questions in that they require «a strongly presupposed context» (see Chang (1977) and Cheng and Rooryck (2000)). This implies that the choice between individual question types is not completely free. On the other hand, fronted Wh- questions also presuppose the proposition expressed in the IP and in the case of adverbial questions such as when and where the adjunct nature of the questioned constituent leads to the strong presupposition in both, insitu and fronted Wh. ${ }^{7}$

Given the input and the (relatively free) choices a French child can make, the investigation of question use is directly relevant for showing that child language opts for economy wherever possible. In addition, a detailed investigation of structural phenomena such as the occurrence of null subjects or infinitives in specific question types can tease apart several suggestions made about early syntax. Two approaches making different predictions with respect to Wh-questions are ATOM (Agreement and Tense Omission Hypothesis) and UCC (Unique Checking Constraint) proposed by Wexler $(1994,1998)$ and the truncation hypothesis as formulated by Rizzi (1994, 2000).

Such an investigation is equally relevant for current hypotheses about Specific Language Impairment (SLI). Recently, the notion of syntactic complexity has been invoked as the underlying difficulty not only by Jakubowicz and Nash (2001) discussed above, but has been advocated as a constraint on non-local dependencies by van der Lely for the last decade, specifically in van der Lely (1998). French Wh-questions therefore emerge as the ideal testing ground not only for typically developing children but also for children with SLI.

\section{Previous results and theoretical approaches}

\subsection{Previous results on typically developing French children}

The first extensive study on questions in child French was Crisma (1992), who investigated the child Philippe from the Leveillé corpus (Suppes, Smith and Leveillé

6. The term is used by Cheng and Rooryck (2000).

7. See also Boskovic (1998), Mathieu (1998) for discussion of French question formation. 
(1973)) available on CHILDES (MacWhinney (2000)). Two of the results from this study are particularly striking.

The first finding was that Philippe used only uninverted fronted Wh-questions for the first 5 months of data-taking and began producing Wh-in-situ only at the age of 2.6. Subsequent research on other children (Hamann (2000), Hulk and Zuckermann (2000), Plunkett (2004)) showed that these start with Wh-in-situ, which is the most economic construction according to the complexity metric. This comparison with other children called in question the explanation envisaged by Crisma for Philippe's preference for fronted Wh, namely that Wh-in-situ leads to a certain clash of the LF-requirements with the surface form (the interpretation requires an operator in the Complementizer Phrase (CP) whereas there is no visible CP). Instead, it was suggested (Hamann $(2000,2002))$ that the reason for Philippe's preference is to be sought in the input he received. The speech of Philippe's parents as documented in the corpus does not contain the in-situ option, which occurs, however, in the speech of the investigator. It can be concluded that Philippe did not have a choice at the beginning of data-taking.

Crisma's second finding was that Philippe did not use infinitives and null subjects in his fronted Wh-questions, though he used both in his declarative structures. This was interpreted by Crisma as confirmation of the prediction that truncation is not possible in fronted Wh-questions (excluding infinitives and null subjects from fronted Wh-questions). This finding was corroborated by Levow (1995) and Hamann (2000) for other children. Both authors did not find infinitives in fronted Wh-questions, Levow reports a marked asymmetry in subject drop in fronted Whquestions and declaratives (5\% vs. 55\%), and Hamann found no null subjects in fronted Wh-questions in the corpus of Augustin and the then available recordings of Marie with the exception of three cases, which all involve pourquoi ('why'). Hamann (2000) extends the investigation to in-situ questions and reports that infinitives do not occur in this construction, whereas null subjects do.

Plunkett (2004) and Plunkett and DeCat (2001) present a study of null subject use by French speaking children from the York corpus. These authors investigated null subject use not only in different constructions but also according to verb type, i.e. in declaratives and questions containing lexical verbs or copulas. Philipps (1995) had pointed out that Crisma's result could be a consequence of a tendency of infinitives and null subjects to occur with lexical verbs, not with auxiliaries and copulas (see also Rasetti (1995)). Because the questions investigated mostly contained a copula or auxiliary, null subjects and infinitives should be rare. This is the idea Plunkett and DeCat (2001) pursue. They find that at least one of the children they investigated produces 6 examples of null subjects in fronted Wh-questions and in this child's production there is no asymmetry in the use of null subjects in fronted Wh and in-situ questions. For this child null subjects occur more often with lexical verbs than with copulas across declaratives and questions. ${ }^{8}$ For Daniel and

8. Plunkett and DeCat (2001) report 11 null subjects in the 102 Wh-questions of the child Max, but do not differentiate in-situ and fronted Wh-questions for this child. In fact, they found practically exclusively in-situ questions for this child (see also Plunkett 2004) so that there were too few 
Augustin, however, null subjects are more frequent with copulas than with lexical verbs and null subjects generally occur with true auxiliaries at a rate of about $25 \%$ in French, see also 2.3.1. It thus seems unlikely that the fronted $\mathrm{Wh} /$ declarative and fronted $\mathrm{Wh} / \mathrm{Wh}$-in-situ asymmetry with respect to null subject use found in the other children can be derived directly from the predominant occurrence of copulas or auxiliaries in questions. ${ }^{9}$

Hamann (2000) attempts to explain the structural asymmetry she found in the children she investigated departing from the assumption that the requirements of interpretation force the child to project as far as CP in both question types. In trying to pinpoint a relevant derivational or representational difference in fronted Wh and in-situ questions, she adopts the analysis of in-situ proposed by Engdahl (1980) and more recently Reinhardt (1998) who suggest that a base-inserted question operator binds a choice function. If this in-situ (and yes-no) question operator is different from the true Wh-operator, then certain other differences might follow, such as the occurrence of null subjects in one type of question but not in the other. In this context the status of pourquoi ('why') becomes crucial. In 1.2. it has already been mentioned that pourquoi ('why') is different from other question words. It does not occur in-situ and it does not occur in Stylistic inversion structures. In adopting Rizzi (1990)'s analysis of Italian perché ('why') and French pourquoi ('why') as base-inserted in the same position as the base-inserted Qmarker (see also Rizzi (1999) and Ko (in press)), Hamann could assimilate the cases of null subjects with pourquoi ('why') to the cases occurring in in-situ questions and to the cases occurring in Early German Wh-less questions or yes-no questions. The mechanism that allowed null subjects to survive in in-situ, yesno and pourquoi ('why') questions was called «by-passing» (Haegeman 2000) and involved the activation of agreement projections as escape hatches. In this paper I present an alternative analysis which does not rely on the by-passing mechanism and arrives at the desired distinction under both analyses of the in-situ phenomenon, a traditional movement analysis and an analysis via base-insertion of

fronted Wh-questions for analysis. In the latter construction, Max did not have null subjects. For the child Anne, they report 6 null subjects in 31 fronted Wh questions (19.3\%) and 33 null subjects in 161 in-situ questions (20.4\%) so that no asymmetry emerges. For Anne, they show that null subjects occur more with lexical verbs than with copulas across declaratives and questions. We will return to this finding later.

9. Rasetti (2003:162) in her careful consideration of factors like verb type and structure, presents the following figures: there are $22.2 \%$ null subjects with lexical verbs vs. $31.7 \%$ null subjects with copulas for Augustin, and $48.8 \%$ null subjects with lexical verbs vs. $64.7 \%$ null subjects with copulas for Daniel. In general null subjects occur with auxiliaries at a respectable percentage in French as can be calculated from the figures given in Rasetti (2003:163) for the children from the Geneva corpus.

Note also that Hamann (2002) investigated Danish children with respect to the occurrence of null subjects in questions and found that null subjects with copulas occurred significantly less in Wh-questions than in declaratives and null subjects with lexical verbs also occurred significantly less in Wh-questions than in declaratives. This is another indication that, even though a significant asymmetry in null subject use with copulas and lexical verbs exists in Danish, there also exists an asymmetry due to structural differences in Wh-questions and declaratives. 
a question operator and a mechanism like unselective binding or the binding of a choice function. ${ }^{10}$

\subsection{Previous results on question formation in children with SLI}

Cross-linguistic results on the production of questions by children with SLI have shown that questions and in particular Wh-questions constitute an area of great and persistent difficulty for language-impaired children. Van der Lely (1998), who elicited questions in English, reports different types of errors. SLI children may move only the operator part of the Wh-phrase, as in examples $(4 a, b)$. If the Whphrase is moved to initial position, they may still show difficulties with the verbal chain, as in (5a), where no verbal element is found in $\mathrm{C}$, and in $(5 \mathrm{~b})$, where the tense feature is spelled out twice. Van der Lely (1998) reports that such errors occur at chance level and therefore proposes an account assuming optional feature checking in non-local configurations. This is defined as the central difficulty of children with SLI called the Representational Deficit of Dependent Relationships (RDDR).

(4) a. What did Mrs. Brown broke something

b. Which did Mr. Green open the door

(5) a. Which cat Mrs. White stroke?

b. Which coat was Prof. Plum weared

In a study on German children with SLI, Hamann et al. (1998) note special difficulties with question formation. In Wh-questions, these authors observe the occurrence of the finite verb in end position, as in (6a), the occurrence of infinitives, as in (6b), and missing subjects as in (6c). None of these errors is found in the questions of normally developing children (Clahsen et al. 1996). As they find that $76 \%$ of all Wh-questions are target inconsistent and identify other CP-related problems such as the occurrence of finite verb forms in sentence- final position or the absence of syntactic focalization and topicalization of arguments, the authors interpret this difficulty as a special problem with the $\mathrm{CP}$ in assuming an underspecification of Comp features.

10. A movement analysis was originally suggested by Chomsky (1976) and developed in Huang (1982) where an in-situ question is derived in parallel to fronted Wh by covert Wh-movement to the specifier of CP. See also Mathieu (1998) who cites intervention effects in order to argue for a movement analysis. An analysis via base insertion of a question operator was first suggested by Baker (1970) and developed by Pesetsky (1987) using unselective binding, a scope marking mechanism introduced by Heim (1982). Chomsky (1995) also mentions unselective binding in connection with in-situ questions. Arguments why binding of a choice function is the better device for capturing the relevant scope properties can be found in Reinhart $(1995,1997)$ or von Stechow $(1999)$. Some of these arguments and a sketch of the in-situ analysis can be found in Hamann (2000) and Hamann (1998). 
(6)
a. Wo das brennt?
where that burns
'Where does it burn?'

b. Wo das denn wohl hingehen? where that then (wohl) fit/go (inf)

'Where might that fit?'

c. Wie geht (das)?

how works

'How does it work?'

In a recent study of French SLI children, Jakubowicz (2004) and Strik (2005) showed in several elicitation experiments that SLI children and typically developing 3 -year-olds produce significantly less long-distance questions than root questions. Instead they produce root questions or simple yes/no questions. In addition, Jakubowicz and colleagues showed that SLI children produce three types of longdistance questions shown in $(7 \mathrm{a}, \mathrm{b}, \mathrm{c})$, the target structure involving complete movement, a medial type and a type leaving the Wh-word in-situ, which is ungrammatical in target French.

(7) a. où tu penses qu'on achète les gateaux?

'Where do you think that we buy cookies?'

b. tu penses que c'est quoi qu'elle a apporté?

You think it is what that she brought?

'What do you think she brought?'

c. *tu crois qu'elle a apporté quoi?

You believe she brought what

'What do you believe she brought?'

Jakubowicz (2004) derives these patterns from the Computational Complexity Hypothesis $(\mathrm{CCH})$ which I have sketched in the introduction.

\subsection{Theoretical approaches to early syntax and to SLI}

Two approaches to early syntax that have explicitly treated infinitives and null subjects in questions are of particular relevance here. These are the Optional Infinitive account proposed by Wexler (1994) and the Truncation account introduced by Rizzi (1994) and their respective subsequent developments.

\subsubsection{The UCC Account}

Wexler (1994) derived the optional use of infinitives from the assumption that tense marking might be missing in child grammar. Schütze and Wexler (1996) extended this account in order to capture the case distribution on subjects found in optional infinitives. They suggested that the Agreement (AgrP) or the Tense Projection (TP) 
can be omitted (ATOM) where omission of tense or agreement will lead to the use of an infinitive but only omission of agreement will lead to the use of a pronominal subject with accusative case (him go) and only omission of tense will license a null subject. This idea was further developed in Wexler (1998) by introducing the Unique Checking Constraint (UCC).

\section{(8) Unique Checking Constraint}

The D-feature of DP can only check against one functional category.

The UCC derives ATOM because the child has to omit either the AgrP or the TP if the subject can only check its D-features against one of these categories but not both. By assuming a principle called «minimize violations», Wexler derives the optionality of infinitive use. The child can choose a finite verb in her numeration, violate the UCC by utilizing AgrP and TP and produce a finite clause, or the child can choose a numeration with a non-finite verb and adhere to the UCC by omitting one of these projections. ${ }^{11}$

These accounts offer a natural explanation of the occurrence of null subjects in non-finite clauses. Such null subjects are PRO and occur in the structures with missing or underspecified tense heads. Null subjects occurring in finite clauses cannot be derived from the UCC. They are assumed to be different from the child null subjects occurring with infinitives and are assimilated to topic-drop (Bromberg and Wexler (1995)). Alternatively, the verb forms are analyzed as disguised non-finite forms, which can license PRO (Wexler 2000).

Note that the UCC predicts that null subjects (and infinitives) are not possible with auxiliaries, which are analyzed as base-inserted in T. Thus they necessarily activate $\mathrm{T}$ and cannot be disguised forms. Though there is a debate about this point (see Plunkett and De Cat (2001) and footnotes 8 and 9), auxiliaries seem to allow null subjects in French. If we leave the copula aside, which indeed shows low rates of subject drop (Rasetti (2003)), null subjects occur with auxiliaries at a rate of $37.9 \%$ in Augustin's speech, at 24.8\% in Marie's and at 28.6\% in Louis's as can be calculated from Rasetti (2003: 163). ${ }^{12}$

One of the predictions of this account of optional infinitives concerns questions. Wexler $(1994,1998)$ predicts that infinitives can occur in Wh-questions because the CP can be projected even though the Tense or the Agreement projection is missing. Bromberg and Wexler (1995) indeed found a high percentage of infinitives in English fronted Wh-questions, data they interpret as evidence for

11. The minimize violations principle does not a priori seem to be an economy constraint. It is more reminiscent of the ranking of constraints in Optimality Theory. In a manuscript version of Wexler (1994) there is an explicit economy calculation showing that the use of a finite verb is as costly as the use a non-finite verb. This calculation makes the standard assumptions of the time (overt movement more costly than LF-movement).

12. See also the discussion in Hamann (2002:234-241) about null subjects and auxiliaries/copulas in Danish. The findings are basically the same as for French: though there is a marked asymmetry in the use of null subjects on copulas and lexical verbs, nevertheless null subjects occur with copulas quite massively $(41 \%)$ in certain files. 
ATOM. Given that adult English has subject auxiliary inversion (SAI), which indicates that in English questions there is a Wh-feature on a verbal element needing to be checked against the Wh-feature on the Wh-word, this conclusion is not trivial. There must be some mechanism in the child grammar that makes such feature checking possible or superfluous when the verb is in the infinitive. Guasti and Rizzi (1996) and Guasti (2000) offer such a mechanism in suggesting that there is a null auxiliary in English child structures such as what you like? or what you doing? These authors rely on the truncation option, however, so that in a UCC account some other mechanism must guarantee the grammaticality of questions when the verb is in the infinitive (and occurs to the right of the subject).

Additional data on null subjects in English questions have lead to much debate. Bromberg and Wexler (1995) and Roeper and Rohrbacher (2000) showed that null subjects occur with infinitives in Wh-questions, but do not occur in finite English Wh-questions. In the ATOM account the interpretation of this fact is that null subjects in infinitival questions are PRO licensed by [-Tns], and finite null subjects could not be licensed in questions since they are dropped topics. ${ }^{13}$

Though French Wh-questions are never explicitly discussed, we might imagine the following argumentation concerning Crisma's (1992) and Levow's (1995) earlier results. Infinitives do not occur in fronted inverted Wh because the verb or auxiliary raises overtly to $\mathrm{C}$, i.e. raises before Spell-out, and thus necessarily passes through T. By the same reasoning as for English questions, infinitives should be possible in in-situ questions and in non-inverted fronted Wh questions because there is no overt verb raising. In addition, if finite null subjects involve topic drop, they are not expected in questions. As it was shown that in non-topic-drop languages finite null subjects cannot be assimilated to topic-drop by Hamann and Plunkett (1998), Wexler (2000) speculates that certain finite verb forms are disguised non-finite forms. If verbs have to raise to $\mathrm{C}$ in fronted $\mathrm{Wh}$ and so pass through $\mathrm{T}$, such disguised non-finite forms should not occur in fronted Wh with inversion, but are expected in fronted Wh without inversion and in in-situ questions, where no (overt) movement has taken place.

This scenario makes the following predictions. Infinitives should not occur in fronted, inverted Wh questions. In contrast, infinitives might be expected in noninverted fronted Wh questions and in in-situ questions. The same holds for null subjects. They are not expected in fronted Wh with inversion, whereas they could occur in fronted Wh without inversion and in in-situ questions. In these constructions they could occur with infinitives and with finite verb forms, which can be disguised non-finite forms in these cases.

\subsubsection{The Truncation Account}

In his original proposal about root infinitives in child language, Rizzi (1994) suggested that the $\mathrm{CP}$, which is the root in adult sentences, is optional in child grammar. This implies that children's sentences do not necessarily involve the CP-layer. 
If there is no morphological material to be accommodated, structures can be truncated leaving the IP or only the VP. In addition, Rizzi postulated that empty categories have to be licensed only if such licensing is possible. Licensing normally takes place in c-command configurations. Such a configuration cannot be created for categories of the root since there is no structure above the root from which such categories could be c-commanded. Therefore, empty categories in the specifier of the root need not fulfill any special licensing conditions. In this framework, infinitives will surface when structure down to and including the TP is truncated. In the remaining structure, an empty category in the specifier of the root will survive, so null subjects can occur with infinitives. Null subjects can also occur with finite constructions if the child has projected as far as TP or AgrP, but has truncated the CP. Note that this account need not postulate two different types of null subject to account for subject drop in infinitival and in finite constructions. Nevertheless, Rizzi (2000) makes use of the PRO null subject, which can always be licensed in non-finite constructions, in order to account for the data on English child questions.

More recently, Rizzi (2000) suggested that two competing principles are responsible for the early grammar, Structural Economy and Categorial Uniformity. In this approach, truncation derives from an economy principle and the CP remains optional as long as the child has not realized that a declarative main clause is of the same semantic type as an embedded clause, necessarily involving the CP.

\section{(9) Structural Economy:}

Use the minimum of structure consistent with well-formedness constraints.

\section{(10) Categorial Uniformity:}

Assume a unique canonical structural realization for a given semantic type.

The theory makes specific predictions about null subjects and infinitives in questions. Because null subjects are restricted to the specifier of the root, it follows that constituent questions with a fronted Wh-word (and finite verb) do not allow null subjects. Because a fronted Wh-word will activate the $\mathrm{CP}$ and will select all the lower projections, infinitives should not occur in constituent questions with a fronted Wh-word either. The latter prediction was confirmed by Crisma (1992) for French and by Clahsen et al. (1996) for German. It also holds for Danish. Hamann (2002) mentions $1.5 \%$ infinitives in Wh-questions for Anne and $4.7 \%$ infinitives in Wh-questions for Jens contrasting with a mean of $27.4 \%$ (Anne) and $23.6 \%$ (Jens) infinitives over all. ${ }^{14}$ In the broader context of cross-linguistic studies, the data on English mentioned in 2.3.1., which at first glance go against the truncation account, seem to require a language-specific treatment. Such treatments have been offered within truncation approaches (see Guasti (2000)), so that these data do not provide absolute evidence against truncation.

14. See Hamann (2002) for a discussion of cross-linguistic data (Danish, English, French and German) and Treichler (in preparation) for some details on Danish. 
For French in-situ questions the scenario is somewhat different. Because of the conflicting evidence of overt syntax and the requirements of interpretation in insitu questions, the child cannot straightforwardly decide whether the $\mathrm{CP}$ is needed in full or can be truncated. If there is such a time of uncertainty, null subjects might be expected in that period. Under the assumption of an articulated CP structure as introduced by Rizzi (1997), such a conflict might not necessarily lead to the conclusion that the child does not interpret an in-situ question as a question. One of the lower Wh-related projections may be active and the rest of the structure, especially the ForceP, may still be truncated.

The predictions about the occurrence of infinitives in in-situ questions depend on assumptions about the checking mechanism in Wh-questions. In order to account for subject/auxiliary and subject/verb inversion Rizzi (1991) introduced the Whcriterion, which requires that the Wh-feature on the Wh-operator be checked by the Wh-feature on a verbal head (and vice versa) in a spec-head configuration. This idea has been recast in terms of Wh-feature checking by Chomsky (1995). One difference between these two accounts is the locus of the uninterpretable Wh-feature that is carried by the verb or the auxiliary. Chomsky (1995) classifies it as a feature of V, whereas Rizzi $(1991,1995)$ claims that it is a feature of T (for languages with subject/aux/verb inversion) or of $\mathrm{C}$ (for languages without inversion). Rizzi (1995) demonstrates that it cannot be a feature of V. If it were and it were a strong feature on a par with other verbal features, then * Whom saw he $t t$ should be grammatical in English. If it were a weak V feature, then we would expect *Whom he saw $t$ to be grammatical. Rizzi's conclusion is that this feature is on T in English, which leads to a natural derivation of $d o$-insertion in T. As mentioned above, this feature can also be in $\mathrm{C}$, which is a possible analysis for French noninverted fronted Wh questions. ${ }^{15}$

We now have two possibilities for French Wh-in situ. In this construction the feature could be in $\mathrm{C}$ or in $\mathrm{T}$. In both cases, $\mathrm{T}$ cannot be truncated. Hence infinitives cannot occur in in-situ questions in this framework. ${ }^{16}$

In particular, we can derive the following predictions. Infinitives should not occur in questions: neither in fronted Wh with inversion, nor in fronted Wh without inversion, nor in in-situ questions. Null subjects should not occur in fronted Wh questions, be they inverted or non-inverted. In contrast, null subjects can occur in in-situ questions, for a certain time at least.

15. See Rizzi (1995) for a full development of these ideas and Guasti and Rizzi (1996) and Guasti (2000) for applying this framework to English child data.

16. The minimal assumption seems to be that the feature is in $\mathrm{T}$ as there is no operator in SpecCP, so placing the feature in $\mathrm{T}$ would allow maximal truncation for the child. If the feature is in $\mathrm{C}$ in parallel to non-inverted fronted Wh, then null subjects could still occur since the specifier is empty. Note that the same assumption (uninterpretable wh-feature on T) will not derive that infinitives do not occur in French questions in the UCC framework. Let us assume that the Wh-feature activates T. Still, infinitives could surface because Agr might be missing. Such infinitives would not allow null subjects across question types. If the feature is in $\mathrm{C}$, then $\mathrm{T}$ or Agr could be missing. 


\subsubsection{Approaches to $S L I$}

Under the assumption that children with SLI show a parallel but delayed, not a deviant development (see Rice and Wexler (1995), Hamann et al. (2003)), there has been a recent trend to transfer the models for early typical development to the grammar of SLI children. Especially the UCC has been invoked to account for the so-called EOI stage found for English SLI (Wexler in press). As truncation has also been suggested as an explanation for certain phenomena found in the speech of SLI children (Hamann 2004), SLI data on the production of questions will give additional evidence for or against one of these suggestions.

The Representation Deficit for Dependent Relations (RDDR) as proposed by van der Lely (1998) states that the data from SLI children are best characterized by assuming a deficit in building non-elementary, complex dependencies. Local dependencies are possible in these children's grammars, whereas long-distance dependencies, i.e. movement, is optional. Van der Lely derives this optionality because she assumes that SLI children have problems with the economy principle of «Last Resort» (Chomsky 1995)). They do not know that movement is obligatory as a Last Resort, i.e. when non-interpretable strong features have to be checked.

Jakubowicz and Nash (2001)'s Hypothesis of Computational Complexity (HCC) will also be considered in connection with the data. These authors define computational complexity with the help of the metric described above and claim that less complex derivations will appear earlier and will be preferred over more complex ones.

\section{Method}

For the investigation of spontaneous speech, the paper is based on the Geneva corpus, specifically on analyses by Rasetti (2003) and Baranzini (2003). The data were thoroughly regrouped and reanalyzed, however, and the theoretical exploration is my own. The same holds for the data from the elicitation experiment in Cronel-Ohayon (2004) and for the additional statistics kindly made available by her on this experiment.

\subsection{Normal Development}

The spontaneous production of 3 typically developing French-speaking children was investigated within an age range of $1 ; 8$ to $2 ; 10$ and a mean length of utterance (MLU) between 1.33 and 4.28. These 3 children are from the Geneva corpus and are known from previous studies such as Hamann et al. (1996), Hamann (2000, 2003), Rasetti (2000, 2003). Marie's corpus is now available on CHILDES. These children have been extensively described by Rasetti (2003) and Baranzini (2003). There are 10 recordings of Augustin between the ages of 2;0.2 and 2;9.30 and an MLU of 2.37 to 4.28, 17 recordings of Marie between the ages of 1;8.26 and 2;6.10 and an MLU of 1.64 to 3.13, and 12 recordings of Louis between the ages of 1;9.26 and 2;3.29 with an MLU of 1.33 to 3.98. These children were analyzed for their use of null subjects and infinitives in declaratives and their question formation was studied separately. Reference will also be made to Philippe with regard to 
question use, quoting Crisma's work. For additional data on the use of null subjects and infinitives, Daniel (1;8.1-1;11.1), Nathalie $(1 ; 9.3-2 ; 3.2)$ and Philippe $(2 ; 1.19-2 ; 6.20)$ were also considered.

\subsection{Children with SLI}

\subsubsection{Spontaneous production}

During the Geneva Interfaculty Project, 11 monolingual French speaking SLI children were recorded every three months over a period of 2 years and 6 months. These children were clinically diagnosed as having SLI by their speech and language therapist, a neuro-psychologist and a neuro-pediatrician. A complete language battery, assessing lexical and semantic, phonological and syntactic aspects of language and a cognitive battery was administered to each child. The characteristics of these children complied with the SLI diagnostic criteria (Leonard (1998)) in that they showed normal cognition (nonverbal IQ $>80$ ) but acquisition difficulties and delay $(<1.25$ SD below the mean on more than 2 language tasks) in the absence of any organic, neurological, hearing or psychiatric abnormality. For the present analysis recordings 1-5, in some cases recordings 1-6, were analyzed fully for question formation giving an age range of $3 ; 10$ to $9 ; 1$. The use of infinitives and null subjects in declaratives was analyzed only in the first and the last recordings. Because 4 children showed a strong development and great differences in the first and the last recording an intermediate, additional recording was analyzed for these 4 children.

As in previous publications (Hamann et al. 2003), it proved useful to separate the children into a younger and an older group by making a cut at 5-years of age at the beginning of recording. ${ }^{17}$ We obtain a younger group comprising Rafaelle

Table 1a. 11 French children with SLI (age range 3;10-9;1).

\begin{tabular}{lllllll}
\hline Child & Session 1 & Session 2 & Session 3 & Session 4 & Session 5 & Session 6 \\
\hline Rafaelle & 3.10 & 4.1 & 4.4 & 4.8 & 4.10 & 5.1 \\
Aurelie & 4.2 & 4.5 & 4.8 & 4.11 & 5.2 & 5.6 \\
Loris & $4.7+4.10$ & 5.0 & 5.3 & 5.6 & 5.9 & 6.0 \\
Corentin & 4.9 & 5.0 & 5.1 & 5.3 & 5.8 & \\
Didier & 4.9 & 4.10 & 5.2 & 5.5 & 5.8 & \\
Martin & 5.0 & 5.3 & 5.7 & 5.10 & 6.1 & \\
Fabrice & 5.7 & 5.10 & 6.1 & 6.5 & 6.8 & 6.11 \\
Noelle & 6.9 & 7.0 & 7.3 & 7.6. & 7.9 & 7.11 \\
Lea & 7.7 & 7.10 & 8.2 & 8.5 & 8.9 & \\
Candide & 7.10 & 8.1 & 8.4 & 8.7 & 8.11 & 9.1 \\
Noa & 7.11 & 8.1 & 8.4 & 8.7 & 8.10 & 91 \\
\hline
\end{tabular}

17. See Hamann et al. (2003) for more discussion of the two groups. One reason for placing a cut at the age of 5 years was that in the first recordings of the younger children ( $<$ five years of age) root infinitives were found whereas these were totally absent from the older children's speech. 
Table 1b. MLUs of the 11 French SLI children at certain recordings.

\begin{tabular}{lllllll}
\hline Child & $\begin{array}{l}\text { Session } \\
\text { Age }\end{array}$ & $\begin{array}{l}\mathbf{1} \\
\text { MLU }\end{array}$ & $\begin{array}{l}\text { Session } \\
\text { Age }\end{array}$ & $\begin{array}{l}\text { 3 } \\
\text { MLU }\end{array}$ & $\begin{array}{l}\text { Session } \\
\text { Age }\end{array}$ & $\begin{array}{l}\text { 5 } \\
\text { MLU }\end{array}$ \\
\hline Rafaelle & 3.10 & 1.902 & 4.4 & 3.135 & 4.10 & 3.0 \\
Aurelie & 4.2 & 3.186 & 4.8 & 3.205 & 5.2 & 3.335 \\
Loris & 4.7 & 3.134 & 5.3 & 4.108 & 5.9 & 3.671 \\
Corentin & 4.9 & 1.778 & 5.1 & 2.467 & 5.8 & 2.038 \\
Didier & 4.9 & 3.091 & 5.2 & 3.583 & 5.8 & 5.795 \\
Martin & 5.0 & 3.738 & 5.7 & 3.667 & 6.1 & 3.566 \\
Fabrice & 5.7 & 3.874 & 6.1 & 2.617 & 6.8 & 3.463 \\
Noelle & 6.9 & 5.054 & 7.3 & 5.037 & 7.9 & 4.699 \\
Lea & 7.7 & 2.772 & 8.2 & 3.433 & 8.9 & 3.728 \\
Candide & 7.10 & 5.184 & 8.4 & 4.695 & 8.11 & 4.066 \\
Noa & 7.11 & 4.296 & 8.4 & 5.207 & 8.10 & 3.631 \\
\hline
\end{tabular}

(3;10-5;1), Aurelie $(4 ; 2-5 ; 6)$, Loris $(4 ; 7-6 ; 0)$, Corentin $(4 ; 9-5 ; 8)$, Didier $(4 ; 9-5 ; 8)$, and Martin $(5 ; 0-6 ; 1)$ and an older group with Fabrice $(5 ; 7-6 ; 11)$, Noelle $(6 ; 9-7 ; 11)$, Lea $(7 ; 7-8 ; 9)$, Candide $(7 ; 10-9 ; 1)$ and Noa $(7 ; 11-9 ; 1)$. Table 1 a shows the ages of these children at all the recordings used in this study, table $1 \mathrm{~b}$ gives their MLUs at 3 stages during the project. Note that the typically developing children and the younger SLI children show the same MLU range with the exception of Didier at session 5 .

\subsubsection{Elicited production of Wh-questions and yes-no questions}

In addition to the analysis of their spontaneous speech, I will use the results of an elicitation experiment reported by Cronel-Ohayon (2004) who tested the same 11 SLI children described above. Cronel-Ohayon (2004) grouped the questions with respect to complexity across yes-no and wh-questions. Therefore yes-no and whquestions were both tested together, so that in the original experiments the items are balanced. As I am primarily interested in Wh-questions, I separate Wh-questions and yes-no questions and by doing so disturb the original balance and as a consequence statistical significance. Therefore the results on elicitation presented later should be regarded as exploratory and suggestive only. Whenever results are statistically significant, I will indicate this in the text. As I do not report on my own results, I will not give the usual tables of conditions and description of variables. I will only describe the salient features of the experiments, so that their relevance becomes clear. For a description of the original experiment, I refer the reader to Cronel-Ohayon's work.

At the point of this experiment the children were aged between 5;4 (Rafaelle) and 9;7 (Noa). Cronel-Ohayon (2004) also tested 11 normally developing children, aged between 4 and 6 with a mean age of 5;1, who were language-matched accord- 
ing to two lexical tasks and one phonological task. The following materials and procedures for elicitation were used. There was a game situation (Experiment 1). This only elicited yes-no questions. Moreover, questions were elicited with lead-ins (Experiment 2) and in a repetition task (Experiment 3).

Experiment 1 was based on a card game where properties of the character on the card had to be guessed in order to obtain the card. There were 3 different conditions. In the free choice condition the child could ask any yes-no question in any form. In the ESK- condition (ESK), the child was told that there would be no answer and no card would be given to her if her question did not start with est-ce que ("is it that'). In the Inversion condition (INV) the child was told that the question had to start with a-t-il, a-t-elle ('has he, has she').

For eliciting yes-no questions with lead-ins Cronel-Ohayon used the paradigm described by Crain and Thornton (1998) employed also by Hulk and Zuckermann (2000) and Jakubowicz (2004). Crucially there is a puppet in the experiment who does not talk to adults, especially not to the experimenter. Therefore the child has to put the questions to the puppet and the experimenter tells the child what to ask. The technique is shown in (11). There were 6 such items for yes-no questions.

(11) Je sais qu'il aime jouer au Gameboy. Demande lui, s' il aime aussi regarder la télé.

I know that he likes to play gameboy. Ask him, if he also likes to watch TV.

Experiment 3 called for the simple repetition of a given question form. For yesno questions, there were inverted questions, see (12), or questions starting with est-ce que ('is it that') as shown in (13). There were 8 items of type (12) and 4 items of type (13).

(12) Aimes tu les glaces au chocolat? like you the ice of chocolate? 'Do you like chocolate ice cream?'

(13) Est-ce que tu vas venir chez moi? is it that you will come to me? 'Will you come to my place?'

For Wh-questions, there were lead-in conditions and repetition conditions. The question words used were comment ('how'), quand ('when'), pourquoi ('why'), où ('where'), quoi ('what'), qui ('who').

The lead-ins used the Crain paradigm exemplified in (14) and (15) with 6 items allowing a choice of construction, i.e. 2 questions each starting with comment ('how'), quand ('when'), and où ('where').

(14) Ce matin il est allé à l'école. Demande lui comment.

'This morning he went to school. Ask him how.' 
(15) Demande lui où il habite.

'Ask him where he lives.'

It has to be noted that (15) may bias towards a question formulation as noninverted fronted Wh, because - unlike in English - the child may repeat the embedded question without any changes in word order and produce a grammatical rootquestion. In contrast, (14) remains relatively neutral between the choice of wh-in-situ and fronting of the Wh-word as an answer.

The repetition tasks for Wh-questions required that the child repeat 4 in-situ questions of the type shown in (16), 4 non-inverted fronted Wh-questions, as shown in (17), and 8 inverted fronted Wh-questions, as shown in (18). It also used KESK questions, not discussed here.

Tu vas aller te cacher où? in-situ you will go you to hide where?

'Where are you going to hide?'

(17) Comment tu fais pour patiner? how you do for to skate 'How do you skate?'

(18) Comment as- tu fait ce dessin? Inverted fronted Wh how have-you made this drawing?

'How did you make this picture?'

\section{Results for normally developing children}

\subsection{Fronted Wh versus Wh-in-situ}

Crisma (1992) divided Phillippe's files into three periods in order to make development visible. Table 2a shows these periods. In the first period, Philippe produces only fronted Wh-questions, in the second period there is one in-situ question, and finally both question types occur, with only a slight preference for fronted Wh. Augustin, the first child from the Geneva corpus, shows a different development. After a first period with only rare questions, we find a period where he almost exclusively uses in-situ questions. In a third period, he starts to use proportionally more fronted Wh-questions, though there still is a huge asymmetry in favour of the in-situ construction. This is shown in table $2 b$.

Marie and Louis, the two other children from the Geneva corpus, who both were younger than Philippe or Augustin when data-taking began, also show a first period with rare question use. Then they both start using in-situ questions systematically, whereas they produce fronted wh-questions only occasionally throughout data-taking. This time of systematic use of in-situ questions can be divided into two periods by grouping three recordings together for each child. This was done, as in Crisma's work, to show development more easily. Table 2c shows Louis's question types and table $2 \mathrm{~d}$ shows Marie's. 
Table 2a. Occurrence of Wh-in-situ and fronted Wh-questions, Philippe.

\begin{tabular}{lcc}
\hline Philippe & \% Wh-in-situ & \% fronted Wh \\
\hline $2 ; 1.19-2 ; 2.17$ & 0 & $100(35)$ \\
$2 ; 2.26-2 ; 3.21$ & $1.3(1)$ & $98.7(78)$ \\
$2 ; 6,13-2 ; 7.18$ & $40.7(81)$ & $59.3(118)$ \\
\hline
\end{tabular}

Table 2b. Occurrence of wh-in-situ and fronted Wh-questions, Augustin.

\begin{tabular}{|c|c|c|c|}
\hline Augustin & & $\% \mathrm{Wh}$ in situ & \%fronted Wh \\
\hline age & mean MLU & & \\
\hline $2 ; 0.2-2 ; 3.10$ & 2.57 & $66.7(2)$ & $33.3(1)$ \\
\hline $2 ; 4.1-2 ; 6.16$ & 2.74 & $94.4(67)$ & $5.6(4)$ \\
\hline $2 ; 9.2-2 ; 9.30$ & 4.0 & $85.0(17)$ & $15.0(3)$ \\
\hline
\end{tabular}

Table 2c. Occurrence of Wh-in-situ and fronted Wh-questions, Louis.

\begin{tabular}{lccc}
\hline Louis & \multicolumn{1}{c}{ \% Wh-in-situ } & \% fronted Wh \\
\hline age & mean MLU & & \\
$1 ; 9.26-2 ; 0.8$ & 1.51 & $62.5(5)$ & $37.5(3)$ \\
$2 ; 1.4-2 ; 2.4$ & 2.69 & $84.2(16)$ & $15.8(3)$ \\
$2 ; 2.17-2 ; 3.29$ & 3.47 & $88.6(31)$ & $11.4(4)$ \\
\hline
\end{tabular}

Table2d. Occurence of wh-in-situ and fronted Wh-questions, Marie.

\begin{tabular}{|c|c|c|c|}
\hline Marie & & $\%$ Wh-in-situ & $\%$ fronted Wh \\
\hline age & mean MLU & & \\
\hline $1 ; 8.26-2 ; 1.7$ & 2.08 & 90.9 (10) & $9.1(1)$ \\
\hline $2 ; 1.18-2 ; 3.3$ & 2.48 & $81.2(26)$ & $18.8(6)$ \\
\hline $2 ; 3.13-2 ; 6.10$ & 2.93 & $80.6(25)$ & $19.4(6)$ \\
\hline
\end{tabular}

Evaluating the data of these four children, it emerges that Philippe seems to have been the exception with his exclusive use of fronted Wh in the first two periods. Wh-in-situ is greatly preferred by the other children, a result also obtained by Plunkett (2004) and Plunkett and DeCat (2001) for the children of the York corpus.

Considering only the contexts where a free choice of question type is possible, a strong preference for Wh-in-situ is revealed for the three Genevan children, as shown in table 3 . This table specifically does not contain pourquoi or quoi questions because the first are possible only in fronted Wh-constructions, the latter only in insitu constructions. 
Table 3. Free choice contexts: (no pourquoi, no quoi).

\begin{tabular}{lcc}
\hline Child & Wh-in-situ & Fronted Wh \\
\hline Augustin & $90.7(49 / 54)$ & $9.3(5 / 54)$ \\
Louis & $73.3(22 / 30)$ & $26.7(8 / 30)$ \\
Marie & $76.1(35 / 46)$ & $23.9(11 / 46)$ \\
\hline
\end{tabular}

In addition to the predominance of in-situ questions, practically all fronted Wh questions are non-inverted. There are a few exceptions in Marie's and Augustin's speech listed as (19) and (20). For both children, the first of these, (19a) and (20a), are rote learned. Augustin's (20a) is from a song and Marie's question (19a) is uttered in the context of a bed-time routine.
b. ou est maman?
where is mommy
'Where is mommy?'
(20) a. ou est tu souriceau? Augustin 2;6
Where are you mouse
'Where are you, mouse?'
b. l' auto à qui conduit papa? Augustin 2;9.30 the car to who drives daddy 'Whose car does daddy drive?'

Marie 1;10.22

Marie 2;3.13

Louis has no inverted fronted Wh-questions. He produces two erroneous uses of fronted quoi ('what'), shown in (21a,b), an element which can only be used insitu. Both are hard to interpret.

(21) a. Quoi ça fait le robe?

Louis $2 ; 2.4$

what that does the dress

'What does the dress do?'

b. Quoi ça fait le robe pour mettre? Louis 2;2.4 what that does the dress for putting

'What does that do for putting the dress on?'

In view of the preferred use of in-situ questions and these rare examples of inversion, it can be safely concluded that children opt for using the economical question forms in the beginning and produce the more complex types with fronting and inversion only later. 
Table 4. The occurrence of 0 -subjects in finite contexts and of infinitives in the speech of Daniel, Nathalie, Philippe and Augustin, Louis and Marie grouped by age

\begin{tabular}{lllll}
\hline age group & $\begin{array}{l}\text { finite null } \\
\text { subjects }\end{array}$ & $\begin{array}{l}\text { \% finite } \\
\text { null subj. }\end{array}$ & $\begin{array}{l}\text { non-adult non-finite } \\
\text { forms (INF+BP) }\end{array}$ & $\%$ \\
\hline $1 ; 8-1 ; 10$ & $140 / 355$ & 39.4 & $288 / 643$ & 44.8 \\
$1 ; 10-2 ; 0$ & $242 / 632$ & 38.3 & $219 / 851$ & 21.1 \\
$2 ; 0-2 ; 2$ & $245 / 677$ & 36.2 & $280 / 1057$ & 26.5 \\
$2 ; 2-2 ; 4$ & $428 / 1911$ & 22.4 & $518 / 2429$ & 21.3 \\
$2 ; 4-2 ; 6$ & $58 / 215$ & 27 & $26 / 241$ & 10.8 \\
$2,6-2,8$ & $91 / 707$ & 12.9 & $64 / 721$ & 8.9 \\
$2 ; 6-2 ; 10$ & $40 / 267$ & 15.0 & $14 / 218$ & 5.0 \\
\hline
\end{tabular}

\subsection{Infinitives and null subjects as an overall phenomenon}

We first establish the rate of occurrence of infinitives and null subjects in the speech of French children. Table 4 shows the overall occurrence of finite null subjects and infinitival forms in the speech of 6 French children. Infinitival forms here include genuine infinitives and bare past participles. This inclusion of past participles avoids the sometimes impossible decision whether a verbal form ending in /e/ is actually an infinitive (travailler 'to work') or a past participle (travaillé 'worked'). We focus on finite null subjects for two reasons. Null subjects in infinitives are to be expected under either of the approaches discussed above and so cannot contribute to a differentiation. Moreover, it will turn out that we find only finite forms in questions. An analysis of null subjects in questions can therefore only be contrasted with the overall occurrence of finite null subjects. As to these two phenomena, we observe that null subjects in finite constructions occur at a higher rate than infinitives and that they linger longer.

\subsection{Infinitives in Declaratives and Questions}

On the basis of these data, we compare declaratives with questions with respect to the use of infinitivals. Table 5 gives an analysis of the occurrence of infinitivals in declaratives, fronted Wh and in-situ questions for the three Genevan children individually, table 6 gives a summary of the data. As there are practically no inverted fronted Wh-questions, the results on fronted Wh hold primarily for fronted-Wh without inversion.

A detailed analysis reveals that Marie has no infinitive or bare participle in her Wh-questions. Louis has one infinitive, see (22), in a fronted Wh-question. As this could be classified as an adult self-commentary, it was not included in the calculation for table 6 .
(22) où ranger ça?
Louis 2.0.8
where put (away) that
'Where to put that away?' 
Table 5. Infinitives and bare participles in declaratives and questions for Augustin, Louis and Marie.

\begin{tabular}{|c|c|c|c|c|c|c|c|c|c|}
\hline & \multicolumn{3}{|c|}{ August. } & \multicolumn{3}{|c|}{ Louis } & \multicolumn{3}{|c|}{ Marie } \\
\hline & decl & fr. Wh & in-situ & decl & fr. Wh & in-situ & decl & fr. Wh & in situ \\
\hline FIN & 663 & 8 & 86 & 897 & 12 & 53 & 1235 & 14 & 62 \\
\hline INF & 82 & 0 & 0 & 141 & 1 & 0 & 179 & 0 & 0 \\
\hline$+\mathrm{BP}$ & & 1 & 1 & & & & & & \\
\hline$\%$ INF & 11.0 & 12.5 & 1.2 & 13.6 & 8.3 & 0 & 12.7 & 0 & 0 \\
\hline
\end{tabular}

Table 6. Summary of the occurrence of infinitives and bare participles in declaratives and questions.

\begin{tabular}{llll}
\hline Aug, Lou, Mar & Type & INF+BP & \%(INF+BP) \\
\hline \multirow{2}{*}{ TOT } & declarative & $402 / 2795$ & 14.4 \\
& fronted Wh & $1 / 24$ & 4.1 \\
& Wh-in-situ & $1 / 201$ & 0.5 \\
\hline
\end{tabular}

Augustin has one bare participle (23a) in a fronted Wh question and one bare participle in an in-situ question (23b). Genuine infinitives ${ }^{18}$, identified in the context as such, do not occur in either construction which is reminiscent of the findings on negation (Hamann (2000b)). ${ }^{19}$
a. ou cachés?
Augustin 2.6.16
where hidden
'Where are/have they hidden?'
b. devissé où?
Augustin 2.6.16
unscrewed where
'Where did you unscrew this?' or
'Where has this been unscrewed?'

Summing up, we can say that infinitives do not occur and bare participles are rare in either fronted Wh and in wh-in-situ in the speech of these three children.

18. Rasetti (2003: 50,54) makes a careful distinction of genuine infinitives and bare participles by context. I use her coding and analysis here.

19. Hamann (2000b) argues that including bare participles with the non-finite forms leads to the high numbers of cases of non-finite verbs occurring in negations known from Pierce (1989). Friedemann (1992) in considering only infinitives arrived at a much lower number of such forms. Hamann (2000b) shows for Augustin that non-finite forms occur at $11.7 \%$ in negative utterances, whereas genuine infinitives only occur to $4.7 \%$ which contrasts with $20.9 \%$ of infinitives in positive utterances. 


\subsection{Finite Null Subjects in Declaratives and Questions}

In the investigation of null subjects, it has to be noted that the results from section 4.3. showed that all questions are finite (except 2 ), so that only a comparison with null subjects in finite constructions is relevant here. In section 2.3. and in footnote 11 it was discussed that in the speech of Augustin null subjects occur with auxiliaries and copulas. For Marie and Louis null subjects occur with auxiliaries (around $25 \%$ ), though they are rare with copulas. So even if there is a predominance of copulas and auxiliaries in questions, null subjects should still be possible especially in Augustin's questions. Tables 7 shows the occurrence of null subjects in finite constructions in different question types and in declaratives for Augustin, Marie and Louis.

We observe that Augustin produces 3 null subjects in fronted wh-questions. All of these occur in pourquoi ('why') constructions, however (see also section 2.1). Philippe also produces one null subject in a fronted wh-question, which happens to be another pourquoi construction. So it appears to be the case that fronted wh-questions do not allow null subjects whereas pourquoi-questions do. Plunkett and DeCat (2001:617) report 5 null subjects in 27 fronted Wh-questions for Anne, but they do not mention which question words are involved. If we assume that none of these is pourquoi ('why'), then this casts some doubt on the attempted generalization, especially as Lewov (1995) gives another two examples of null subjects in fronted Wh, one with où ('where') and one with quoi ('what') and we have the additional example où pose from Louis in table 7. In view of the fact that only 8

Table 7. Finite null subjects in different contexts: Augustin, Louis, and Marie.

\begin{tabular}{lcccll}
\hline & & INF & $\begin{array}{l}\text { \% 0-subject } \\
\text { in declaratives }\end{array}$ & $\begin{array}{l}\text { \% 0-subject } \\
\text { in Wh in situ }\end{array}$ & $\begin{array}{l}\text { \% 0-subject } \\
\text { in fronted Wh }\end{array}$ \\
\hline $\begin{array}{l}\text { Augustin } \\
\text { age }\end{array}$ & mean MLU & & & & \\
$2 ; 0.2-2: 3.10$ & 2.57 & 26.5 & 34.1 & $0(0 / 1)$ & $0(0 / 2)$ \\
$2 ; 4.1-2 ; 6.16$ & 2.74 & 12.9 & 39.6 & $34.3(23 / 67)$ & $75.0(3 / 4)$ \\
$2 ; 9.2-2 ; 9.30$ & 4.0 & 5.5 & 15.5 & $0(0 / 17)$ & $0(0 / 2)$ \\
\hline $\begin{array}{l}\text { Louis } \\
\text { age }\end{array}$ & mean MLU & & & & \\
$1 ; 9.26-2 ; 0.8$ & 1.51 & 37.7 & 56.7 & $0(0 / 5)$ & $33.3(1 / 3)$ \\
$2 ; 1.4-2 ; 2.4$ & 2.69 & 12.5 & 29.6 & $12.5(2 / 16)$ & $0(0 / 3)$ \\
$2 ; 2.17-2 ; 3.29$ & 3.47 & 3.9 & 9.6 & $0(0 / 31)$ & $0(0 / 4)$ \\
\hline Marie & & & & & \\
age & mean MLU & & & & \\
$1 ; 8.26-2 ; 1.7$ & 2.08 & 22.4 & 28.5 & $10.0(1 / 10)$ & $0(0 / 1)$ \\
$2 ; 1.18-2 ; 3.3$ & 2.48 & 19.6 & 21.3 & $15.4(4 / 26)$ & $0(0 / 6)$ \\
$2 ; 3.13-2 ; 6.10$ & 2.93 & 5.8 & 12.5 & $0(0 / 25)$ & $0(0 / 6)$ \\
\hline
\end{tabular}


such examples have been reported in the literature in the data of 11 children, I feel justified in pursuing an analysis which assumes that null subjects occur with fronted pourquoi ('why') but very rarely with other fronted question words. As the special syntactic status of pourquoi, perché and why has been the focus of much recent work (see Rizzi (1990, 1999) and Shlonsky (in preparation) for proposals about the syntactic analysis of adult pourquoi and why and Thornton (2004) for an analysis of child why-questions), an analysis of child question formation will be suggested in section 7 which takes this fact into account. ${ }^{20}$

It can be observed for the three children that null subjects in fronted Wh questions are practically absent, whereas all three children produce at least some null subjects in wh-in-situ in their respective second phase. Augustin's particularly high rate of such null subjects finds its explanation in the fact that he drops c' ('this') quite frequently, so that est ou (is where) and est quoi (is what) alternates with c'est ou ('this is where-where is it') and c'est quoi ('this is what - what is it'). The other children do not drop ce ('this') in these constructions. This can be due to the frequency of the c'est... ('this is...'), which could be learned as a routine. If this is the case, the rarety of null subjects in copula constructions finds a natural explanation.

In addition table 7 shows that null-subjects vanish faster in in-situ questions than in declaratives. This observation is originally due to Plunkett (2004), who reports high rates of null subjects in wh-questions for the two children Max and Anne and draws attention to the fact that in questions null subjects may disappear faster than in declaratives (as shown in Table 8 for Max, adapted from Plunkett (2004)). Note, however, that for Max all these Wh-questions are in-situ questions.

The basic results from the study of the spontaneous production of 3 normally developing French children are that they prefer the question types in-situ and non-

Table 8. Finite null subjects in Wh (in-situ), adapted from Plunkett (2004).

\begin{tabular}{lllll}
\hline Child & Age & Declaratives & \multicolumn{2}{l}{ Wh-questions (in-situ) } \\
\hline Max & $2.0 .14-2.0 .28$ & $65 \%$ & $93 \%$ & $(13 / 14)$ \\
& $2.1 .16-2.5 .15$ & $22 \%$ & $0.5 \%$ & $(3 / 63)$ \\
& $2.5 .29-2.9 .12$ & $9 \%$ & 0 & $(0 / 12)$ \\
\hline \multirow{2}{*}{ Anne } & $1.11 .13-2.2 .0$ & $44 \%$ & $78 \%$ & $(18 / 23)$ \\
& $2.2 .30-2.10 .18$ & $27 \%$ & $31 \%$ & $(33 / 159)$ \\
& $2.11 .2-3.0 .2$ & $1 \%$ & 0 & $(0 / 19)$ \\
\hline
\end{tabular}

20. Note also that the special status of pourquoi ('why') has not been postulated because of the findings in child language, but that Rizzi $(1990,1999)$ argues for base inserted pourquoi ('why') on independent syntactic grounds that are discussed in Hamann (2000) and which I will come back to in section 7. Plunkett (2004), in her discussion of Hamann (2000), assumes that pourquoi ('why') should be treated as any other question word and proceeds to show that, under that assumption, Hamann's data do not show any asymmetry in null subject use in in-situ questions and fronted Wh-questions. There is no argument, however, showing how its special properties (no occurrence in-situ, no stylistic inversion) can be derived if pourquoi ('why') is indeed to be analyzed on a par with other question words. 
inverted fronted Wh over the Standard French construction with Wh-fronting and inversion. By the complexity metric introduced by Jakubowicz and Nash (2004), the preferred colloquial constructions are more economical than the construction from standard French.

Moreover, infinitives do not occur and bare participles are rare in all types of questions. As to null subjects, they are rare in fronted wh-questions, which are practically all non-inverted in these children's speech. They do occur in in-situ questions for a short time in the recordings of all three children, where they vanish faster than in declaratives. Note that for Augustin, who was recorded up to the age of 2;9, null subjects do no longer occur in his third period when fronted Wh occurs more systematically.

These results indicate that child grammar is economy driven in the sense that given a choice between two grammatical constructions with essentially the same interpretation, the child will choose the one with the less complex derivation. The results also show that the truncation account covers the data, whereas there are some difficulties for a UCC account. The following findings would require some additional apparatus in the UCC account: the absence of infinitives from all question types, the different patterns concerning null subjects found in different question types: occurrence in in-situ questions, absence from fronted wh with or without inversion. All of these results are either predicted by or are compatible with truncation. Before I sketch a child grammar which incorporates elements from representational economy as used in truncation and elements from derivational economy as suggested by Jakubowicz and Nash (2001), I will present data from SLI children which may provide some crucial evidence. ${ }^{21}$

\section{Results for French children with SLI}

\subsection{Fronted Wh versus Wh-in-situ}

With regard to question production the corpora show two types of SLI children, independent of age or MLU. The first type of SLI child resembles typical children with respect to the rate of question use and the preference for wh-in-situ over fronted Wh. ${ }^{22}$ Table 9, in which the analysis is restricted to the first 5 or 6 recordings, shows that Rafaelle, Aurélie, Loris, Martin and Noelle fall into this category. Table 10 shows their strong preference for wh-in-situ in free choice contexts.

Corentin, Didier, Fabrice, Lea, Candide and Noa exemplify the second type of SLI child, marked in grey in table 9 and 10. In the 5 or 6 recordings analyzed by

21. Under the parallelism assumption, SLI data may provide a slow-motion close-up of developmental phases that are blurred in the speed of typical development.

22. Neither inversion nor ESK, KESK were used spontaneously. Cronel-Ohayon (2004) examined all 105 existing files and found a total of $853 \mathrm{wh}$ and yes-no questions. In these 853 questions only 4 inversions occurred (in the very last files of two children) amounting to $0.5 \%$, and only 19 ESK or KESK constructions were found, which amounts to $2.2 \%$. Note that for the typical children these forms are also rare but start to be productive in the later recordings. Marie has 5 KESK forms in 13 fronted Wh-questions, whereas Rafaelle never produces such a form spontaneously. 
Table 9. Occurrence of wh-in-situ and fronted Wh-questions.

\begin{tabular}{lllllll}
\hline Child & Age & Mean MLU & Wh-in-situ & Fronted Wh & Total \\
\hline younger & group & & & & & \\
\hline Rafaelle & $3.10-5.1$ & 2.75 & 20 & 68.9 & 9 & 11 \\
Aurélie & $4.2-5.6$ & 3.24 & 76 & 87.3 & 12 & 87 \\
Loris & $4.7-6.0$ & 3.68 & 35 & 74.5 & 12 & 37 \\
Corentin & $4.9-5.8$ & 2.09 & 3 & 100 & 0 & 13 \\
Didier & $4.9-5.8$ & 3.46 & 12 & 92.3 & 1 & 82 \\
Martin & $5.0-6.1$ & 3.71 & 54 & 65.8 & 28 & 8 \\
\hline older & group & & & & & 29 \\
\hline Fabrice & $5.7-6.11$ & 3.40 & 7 & 87.5 & 1 & 7 \\
Noelle & $6.9-7.11$ & 4.93 & 20 & 68.9 & 9 & 6 \\
Lea & $7.7-8.9$ & 3.31 & 5 & 71.4 & 2 & 3 \\
Candide & $7.10-9.1$ & 4.64 & 5 & 83.3 & 1 & 2 \\
Noa & $7.11-9.1$ & 3.99 & 1 & 33.3 & 2 & \\
\hline
\end{tabular}

Baranzini (2003) they produce less than 15 questions each. This cannot be due to the situational context because the investigator started each session with the same material for each child, a story book, questions about the recent holiday or about school depending on the session. It can therefore be claimed, that these children avoid the use of questions. Moreover, they show a huge asymmetry in their preference of in-situ questions, and 3 of these six children never produce a fronted Wh-question spontaneously in a context where a choice is possible, as table 10 demonstrates.

Table 10. Question types in Free choice contexts (no pourquoi, no quoi, only main questions).

\begin{tabular}{lllll}
\hline Child & Wh-in-situ & \multicolumn{3}{l}{ Fronted Wh } \\
\hline younger & group & & & $(9 / 18)$ \\
Rafaelle & 50.0 & $(9 / 18)$ & 50.0 & $(10 / 57)$ \\
Aurélie & 82.5 & $(47 / 57)$ & 17.5 & $(3 / 19)$ \\
Loris & 84.2 & $(16 / 19)$ & 15.8 & $(0 / 1)$ \\
Corentin & 100.0 & $(1 / 1)$ & 0 & $(1 / 9)$ \\
Didier & 88.9 & $(8 / 9)$ & 11.1 & $(6 / 28)$ \\
Martin & 78.6 & $(22 / 28)$ & 21.4 & \\
older & group & & & $(9 / 19)$ \\
\hline Fabrice & 100.0 & $(7 / 7)$ & 0 & $(2 / 3)$ \\
Noelle & 52.6 & $(10 / 19)$ & 47.4 & \\
Lea & 33.3 & $(1 / 3)$ & 66.7 & $(2 / 3)$ \\
Candide & 100.0 & $(3 / 3)$ & 0 & \\
Noa & 33.3 & $(1 / 3)$ & 66.7 & \\
\hline
\end{tabular}




\subsection{Infinitives and Null Subjects as an overall phenomenon}

In previous research (Hamann et al. (2003)), it was established that in the younger group all children start with infinitive use ranging from $5.7 \%$ to $70 \%$. Rafaelle and Corentin are the two children producing $70 \%$ infinitives in their first recording, a rate that is much higher than infinitive use in typically developing children (table 4). Both these children make progress, however, so that infinitive use is less than $10 \%$ about a year later. All of the younger children drop subjects at rates between $12.4 \%$ and $75 \%$. These trends can be observed in tables $11 \mathrm{a}, \mathrm{b}$, which concern individual children.

In the older group no infinitive use was observed (0.3-2.3\%), though some subject drop was found (3.6-9.5\%). This mirrors the tendency observed for normally developing children, namely that null subjects linger longer than infinitives.

In section 4.4., Rafaelle, Aurélie and Martin will be analyzed in more detail, so that it is useful to present their infinitive and null subject rates file by file as far as analyses have been performed. Rafaelle, as was already pointed out, has a high infinitive rate, and her null subject rate is high as well. Null subjects, like infinitives, vanish fast, however. Table 11a reports Baranzini's (2003) findings on null subjects for this child with previous analyses on infinitives (Hamann et al. (2003), Hamann (2004)) supplementing the data. Table 11b shows Baranzini's findings for Martin. His use of infinitives and null subjects in declaratives at the age of 5;0 resembles that of typical children at the end of the optional infinitive phase. $\mathrm{He}$ has $13.3 \%$ infinitives and a higher rate of subject drop. Both phenomena have vanished from his speech a year later.

There was no notable development in Aurélie's speech concerning her use of infinitives and null subjects in declaratives. This absence of development can also be seen in table 2 showing her almost constant MLU. In order to arrive at a comparison with her use of null subjects and infinitives in questions, I extrapolate for declaratives: at 4;2 she has 5.6\% infinitives and at 5;6 she has $4.2 \%$, so I assume $4.9 \%$ throughout. At $4 ; 2$ there are $12.7 \%$ null subjects and at $5 ; 6$ there are $9.5 \%$, so I assume $11.1 \%$ in all three periods.

Table 11a. Rafaelle's use of infinitives and finite null subjects in declaratives.

\begin{tabular}{lllllll}
\hline Rafaelle & $\mathbf{3 . 1 0}$ & $\mathbf{4 . 1}$ & $\mathbf{4 . 4}$ & $\mathbf{4 . 8}$ & $\mathbf{4 . 1 0}$ & $\mathbf{5 . 1}$ \\
\hline infs & $70 \%$ & $44 \%$ & $20 \%$ & $3.7 \%$ & $1.8 \%$ & $0 \%$ \\
0-s fin & $0 \%$ & $32.8 \%$ & $36.7 \%$ & no data & no data & $9.9 \%$ \\
\hline
\end{tabular}

Table 11b. Martin's use of infinitives and finite null subjects in declaratives.

\begin{tabular}{llll}
\hline Martin & $\mathbf{5 . 0}$ & $\mathbf{5 . 7}$ & $\mathbf{6 . 1}$ \\
\hline infs & $13.3 \%$ & $0.4 \%$ & $2.1 \%$ \\
0-s fin & $24.8 \%$ & $8.5 \%$ & $1.8 \%$ \\
\hline
\end{tabular}


Table 12. Occurrence of infinitives in declaratives and questions for the younger SLI children.

\begin{tabular}{lll}
\hline Context & INF & \% INF \\
\hline Declarative & $170 / 2682$ & 6.3 \\
fronted Wh question & $2 / 78$ & 2.6 \\
Wh-in-situ & $2 / 204$ & 1.0 \\
yes-no & $2 / 164$ & 1.2 \\
\hline
\end{tabular}

\subsection{Infinitives in Declaratives and Questions}

In the younger group Rafaelle, Aurélie, Loris and Martin produce questions at a normal rate, whereas Corentin and Didier only use questions sporadically. Table 12, adapted from Baranzini (2003), gives an overview of infinitive use for the younger group. The overall low rate of infinitive use is due to the fast development observed in these children. Moreover, Baranzini analyzed declaratives only for session 1, 3, 6 for Rafaelle, 1 and 6 for Aurélie, 1 and 4 for Corentin, 1 and 6 for Loris, 1, 3 and 6 for Didier and 1, 3 and 6 for Martin.

A very low rate of infinitive use in questions is observed when averaged over these six children. In declaratives, we find a slightly higher rate. For Rafaelle, a child who uses many infinitives and asks questions at a normal rate, we can select a session where infinitives still occur systematically and some questions occur. At age 4;4 (see also table 11a) she has $20 \%$ infinitives in her declaratives, $14 \%(1 / 7)$ infinitives in fronted Wh-questions and no infinitive in her in-situ questions.

The older group was not analyzed. This is justified because there were practically no infinitives and very few questions in the production of these children.

\subsection{Finite null subjects in declaratives and questions in the SLI children's production}

For the analysis of null subjects in the younger group the focus is on Rafaelle, Aurélie and Martin because these children produce a reasonable amount of questions. Loris will be analyzed for comparison. Corentin and Didier, who have a low question use will not be considered individually.

As to question use, Rafaelle's and Aurélie's recordings can be grouped into three periods. Martin's questions are extremely frequent from the start, however, so that only two periods were assumed. In the respective last periods, question use seems to stabilize and, at least in the case of Martin, in-situ and fronted Wh attain similar frequencies. Tables 13a-c show that all three SLI children allow null subjects in yes-no questions and in-situ questions, but also in fronted Wh. The latter phenomenon is particularly noticeable in Martin. Under the assumption of a parallel but delayed development, the occurrence of null subjects in in-situ questions is expected. Tables 13a-c also indicate that null subjects disappear faster from questions than from declaratives, just as for typical children. SLI children seem to differ from 
their typically developing peers in that they sometimes allow null subjects in fronted Wh-questions: SLI children allow subject drop in all question types.

The last child in the younger group with a normal rate of questions is Loris. Previous research (Hamann (2004)) reported that his difficulties are to be attributed more to the nominal than to the verbal domain. In particular, his developmental profile was very different from that of Rafaelle. His profile for infinitives and null subjects resembles that of the typical children more than that of the three SLI children in that he has no infinitives and only one null subject in his questions, which occurs in an in-situ question, as shown in table $13 \mathrm{~d}$.

As to the older group, only Noelle seems to use questions in a productive way. As none of the children in this group produces many infinitives or null subjects, a

Table 13a. Rafaelle's use of finite null subjects in different contexts.

\begin{tabular}{|c|c|c|c|c|c|c|c|}
\hline Rafaelle & $\begin{array}{l}\text { mean } \\
\text { MLU }\end{array}$ & $\begin{array}{l}\text { Infs } \\
\text { (mean) }\end{array}$ & $\begin{array}{l}\text { 0-subj. } \\
\text { in declaratives }\end{array}$ & $\begin{array}{l}\text { \% 0-subjects } \\
\text { in Wh-in-situ }\end{array}$ & $\begin{array}{l}\% \text { 0-subjects } \\
\text { in fronted Wh }\end{array}$ & $\begin{array}{l}\% \\
\text { in y }\end{array}$ & $\begin{array}{l}\text { ubjects } \\
\text { no }\end{array}$ \\
\hline $3.10-4.1$ & 2.6 & 57 & 33 & - & $33.3 \quad(1 / 3)$ & 42.9 & $(3 / 7)$ \\
\hline $4.4-4.8$ & 3.7 & 11.8 & 36.8 & $33.3(2 / 6)$ & $60.0(3 / 5)$ & 50 & $(2 / 4)$ \\
\hline $4.10-5.1$ & 3.32 & 0.9 & 9.9 & $(0 / 12)$ & 0 & 0 & $(0 / 8)$ \\
\hline
\end{tabular}

Table 13b. Aurélie's use of finite null subjects in different contexts.

\begin{tabular}{llllllllll}
\hline Aurélie & $\begin{array}{l}\text { mean } \\
\text { MLU }\end{array}$ & $\begin{array}{l}\text { Infs } \\
\text { (mean) }\end{array}$ & $\begin{array}{l}\text { 0-subj. } \\
\text { in declaratives }\end{array}$ & \multicolumn{2}{c}{$\begin{array}{l}\text { \% 0-subjects } \\
\text { in Wh-in-situ }\end{array}$} & \multicolumn{2}{c}{$\begin{array}{l}\text { \% 0-subjects } \\
\text { in fronted Wh }\end{array}$} & \multicolumn{2}{l}{$\begin{array}{l}\text { \% 0-subjects } \\
\text { in yes-no }\end{array}$} \\
\hline $4.2-4.5$ & 3.19 & 4.9 & 11.1 & 50 & $(1 / 2)$ & 0 & $(0 / 17)$ & 0 & $(0 / 3)$ \\
$4.8-4.11$ & 3.25 & 4.9 & 11.1 & 13.5 & $(5 / 37)$ & 0 & $(0 / 4)$ & 15.4 & $(2 / 13)$ \\
$5.2-5.6$ & 4.17 & 4.9 & 11.1 & 0 & $(0 / 22)$ & 20 & $(1 / 5)$ & 0 & $(0 / 15)$ \\
\hline
\end{tabular}

Table 13c. Martin's use of finite null subjects in different contexts.

\begin{tabular}{|c|c|c|c|c|c|c|c|c|c|}
\hline Martin & $\begin{array}{l}\text { mean } \\
\text { MLU }\end{array}$ & $\begin{array}{l}\text { Infs } \\
\text { (mean) }\end{array}$ & $\begin{array}{l}\text { 0-subj. } \\
\text { in declaratives }\end{array}$ & & $\begin{array}{l}\text { bjects } \\
\text {-in-situ }\end{array}$ & & $\begin{array}{l}\text { Ibjects } \\
\text { ted Wh }\end{array}$ & & $\begin{array}{l}\text { abjects } \\
\text { no }\end{array}$ \\
\hline $0-5.7$ & 3.7 & 8.6 & 16.6 & 5 & 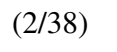 & 25.0 & $716)$ & & $(2 / 27)$ \\
\hline $.10-6.1$ & 3.60 & 2.5 & 2.0 & 0 & $(0 / 14)$ & 0 & $(0 / 11)$ & 2.7 & $(1 / 37)$ \\
\hline
\end{tabular}

Table 13d. Loris's use of finite null subjects in different contexts.

\begin{tabular}{llllllllll}
\hline Loris & $\begin{array}{l}\text { mean MLU } \\
\text { (extrapolated) }\end{array}$ & $\begin{array}{l}\text { Infs } \\
\text { mean }\end{array}$ & $\begin{array}{l}\text { 0-subj. in declar. } \\
\text { (mean) }\end{array}$ & \multicolumn{2}{c}{$\begin{array}{l}\text { \% 0-subjects } \\
\text { in Wh-in-situ }\end{array}$} & \multicolumn{2}{c}{$\begin{array}{l}\text { \% 0-subjects } \\
\text { in fronted Wh }\end{array}$} & $\begin{array}{l}\text { \% 0-subjects } \\
\text { in yes-no }\end{array}$ \\
\hline $4.7-4.10$ & 3.134 & 8.6 & 15.6 & 0 & $(0 / 2)$ & 0 & $(0 / 1)$ & 0 & $(0 / 6)$ \\
$5.0-5.3$ & 3.6 & 2.4 & ca. 5.0 & 7.7 & $(1 / 13)$ & 0 & $(0 / 2)$ & 5.8 & $(1 / 17)$ \\
$5.6-6.0$ & 3.8 & 4.5 & ca. 5.0 & 0 & $(0 / 20)$ & 0 & $(0 / 9)$ & 13.3 & $(2 / 15)$ \\
\hline
\end{tabular}


detailed analysis was not performed. Infinitives and null subjects were not observed in any question type.

In the SLI children we thus find parallels and differences to the typically developing children. It was observed that some SLI children use questions only sporadically. If they produce questions, however, SLI children are like typical children, in that they prefer Wh-in-situ over fronted Wh, they rarely use infinitives in their questions, they omit subjects in Wh-in-situ (and in yes-no questions), and null subject use decreases faster in questions than in declaratives. Note also that this generally occurs in the last period, very clearly for Martin, who produces fronted Wh as frequently as in-situ questions in that period. Unlike normal children, however, SLI children avoid inversion altogether and they also avoid ESK and KESK. Moreover, SLI children who produce questions at a high rate, seem to allow subject omission in fronted Wh. This can be clearly observed in Martin's speech, but also holds for Rafaelle and Aurélie.

\section{Confirming and extending the results for SLI children in elicitation experiments}

With regard to the elicitation experiment conducted with these children, I will focus only on the tendencies which are important for the argument. For a more detailed exposition I refer the reader to Cronel-Ohayon (2004).

\subsection{Yes-no questions}

Globally, the experiments corroborated what was also observed for spontaneous production: a strong tendency to avoid complex constructions such as fronted Wh with inversion. In particular, SLI children never used inversion spontaneously in yes-no questions. In the free game situation in Experiment 1, figure 1, they preferred to use an SVO pattern marking question force only by intonation. The same holds for the lead-in experiment, Experiment 2, shown in figure 2. The same tendencies are observed for typically developing children, however, and the differences are not significant.

In the game situation of Experiment 1 (figure 1), however, SLI children had significantly more difficulties than controls when asked to begin with an inverted structure $a-t-i l$ - ('has he'). SLI children only succeeded in $48.5 \%$ of the cases whereas the controls were $77.5 \%$ correct $(t(10)=-3.46, p<0.01)$. The same picture emerges from the repetition experiment, Experiment 3 (figure 3). SLI children repeated inverted questions correctly only at $72.7 \%$ whereas the controls were $95.5 \%$ correct. This difference was significant $(t(10)=2.31, \mathrm{p}<0.025)$.

It therefore emerges that typically developing children will avoid inversion if left to their own devices, but are well capable of producing inverted structures when they are asked to do so. SLI children, on the other hand, have great difficulties producing these structures. 


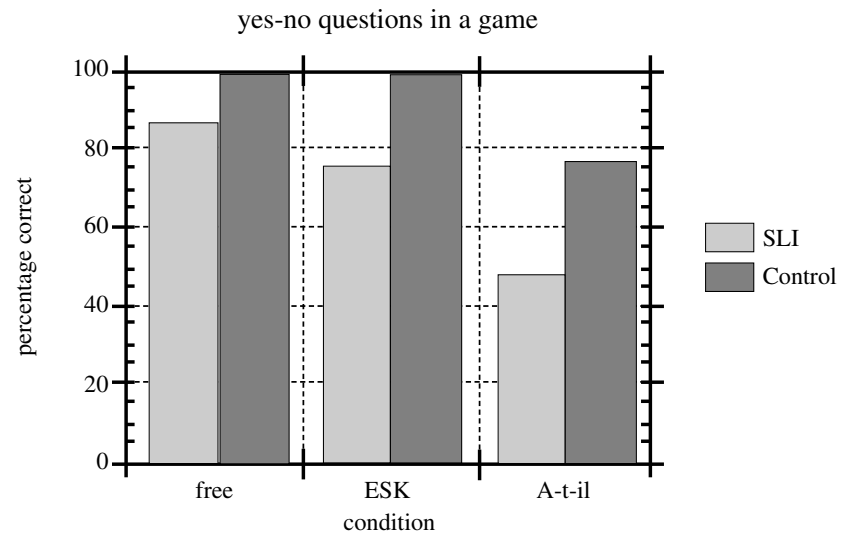

Figure 1. The production of yes-no questions by 11 SLI and 11 control children in a free condition, a condition where the question should start with ESK and a condition where it should start with $A$-t-il ('has-t-he').

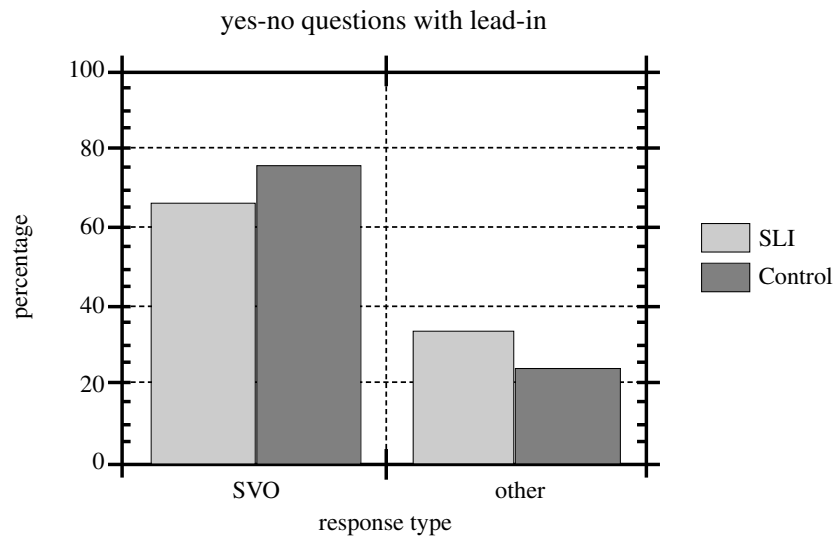

Figure 2. The free production of yes-no questions by 11 SLI and 11 control children given a lead-in such as (11) Demand lui s'il aime aussi regarder la télé ('ask him if he also likes to watch television').

The error analysis conducted by Cronel-Ohayon (2004) indicated that the greatest difficulty for SLI children is producing an inverted structure. In the inversion condition of Experiment 1, where they were asked to start their question with $a-t$ il ('has-t-he') children either did not comply with this instruction using SVO, ESK or KESK or - and this was the most frequent error occurring 19 times - they started with $a-t-i l$ and then added an SVO structure, often repeating the subject and the 


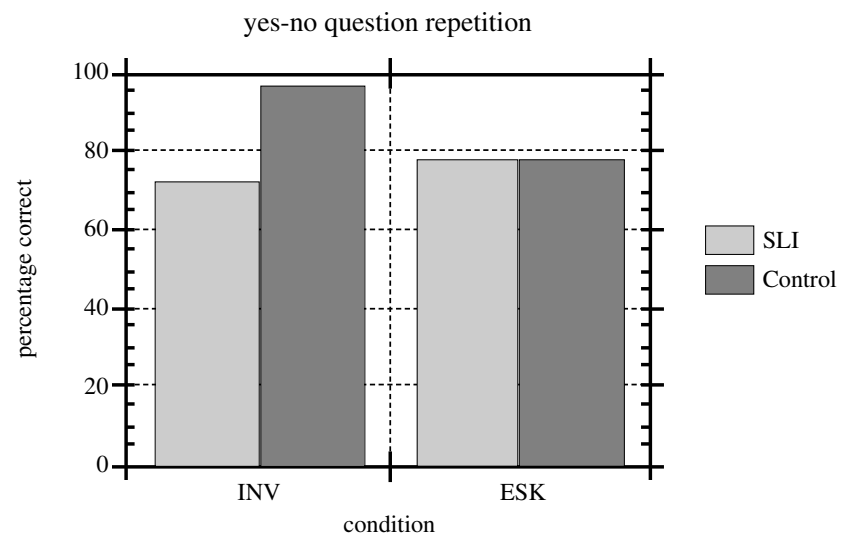

Figure 3. The repetition of yes-no questions starting with ESK and the repetition of inverted yes-no questions by 11 SLI and 11 control children.

verb. Examples (24a) and (24b) are of this type. The error suggests that 'a-t-il' is analyzed as a sort of question marker like ESK, see (24c) for this similarity. In some cases, another question marker was added, as shown in example (25). Table 14 shows the distribution of these errors.

(24) a. a- t-il il a un chapeau? has-t-he he has a hat

'Does he have a hat?'

b. a- t-il c' est un monsieur ?

(1 error SLI, 1 error control) has-t-he this is a gentleman 'Is it a man?'

c. a- t-il qu' il a un chapeau? (8 errors SLI, not in controls) has-t-he que/that he has a hat 'Does he have a hat?'

(25) a- t-il est-ce qu' il sourit?

(0 error SLI, 2 errors in 3.11 has-t-he is it that he smiles year old control)

Table 14. Error distribution for the inversion condition in free yes-no elicitation.

\begin{tabular}{lllllll}
\hline & SVO & ESK & KESK & a-t-il & other & total \\
\hline SLI & 9 & 9 & 2 & 19 & 6 & 45 \\
Control & 1 & 6 & 0 & 3 & 2 & 12 \\
\hline
\end{tabular}


Table 15. errors in the repetition of yes-no with inversion.

\begin{tabular}{lllllll}
\hline & SVO & null subj & double subj & ESK & other & total \\
\hline SLI & 9 & 3 & 3 & 2 & 7 & 24 \\
Control & 2 & 0 & 0 & 0 & 1 & 3 \\
\hline
\end{tabular}

In the inversion condition of the repetition experiment, this particular type of error did not occur, see table 15 . The most frequent error was the use of a simple SVO structure. Interestingly, as in spontaneous production, we find the omission of subjects (26a), but also the doubling of subjects (26b).

(26) a. vas au parc après l' école?

Aurélie 5.5

go to park after the school

'Do you go to the park after school?'

b. tu connais tu les cartes Pokemons

Noelle 7.11

you know you the cards Pokemons

'Do you know the Pokemon cards?' 6

\subsection{Wh-questions}

The elicitation of Wh-questions corroborated the strong preference for wh-in-situ found also in spontaneous production. Experiment 4, which used the Crain-Thornton paradigm with two different types of lead-ins, could not be statistically analyzed because there were not enough items (see Cronel-Ohayon (2004) for statistics in a different grouping of conditions). Therefore only tendencies can be described. It can be observed, however, that SLI children are more reluctant to use fronting of the Wh word than the control children. Two lead-ins were used introduced in section 3.2.2 as (14) and (15). Note that (14) also called lead-in 1 ce matin il est allé à l'école, demande lui comment ('This morning he went to school. Ask him how') remains relatively neutral, whereas there may be a bias for using fronted Wh through simple repetition with lead-in (15) (also called lead-in 2) demande lui où il habite ('ask him where he lives'). The figures 4 and 5 give the percentages separately for the two conditions, lead-in 1 and lead-in 2. A comparison shows that lead-in 2 indeed elicited more fronted wh-questions than lead-in 1 . When averaged over the two types of conditions SLI children produced $50.4 \%$ of fronted wh-questions whereas the controls produced $64.6 \%$. Moreover, SLI children produce almost twice as many in-situ questions than the controls ( $40.4 \%$ vs. $24.2 \%)$. The averages used here in the text may blur the sharpness of the result as they include the bias towards fronting the wh-word in lead-in 2.

Figure 4, separating the conditions, indicates that SLI children use as many insitu questions as fronted Wh in the neutral condition, whereas the controls used about twice as many fronted than in-situ questions. 


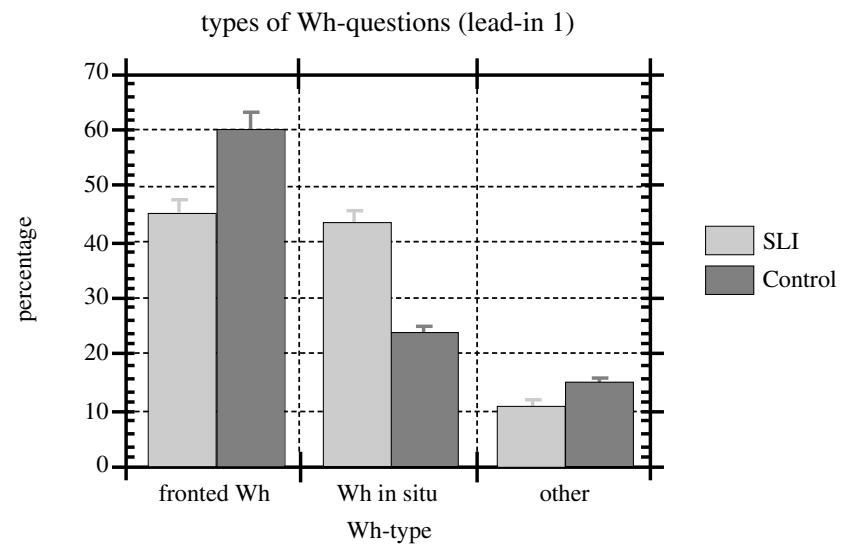

Figure 4. The production of wh-questions by 11 SLI and 11 control children elicited with the neutral lead-in of type (14) as in ce matin il est allé à l'école, demande lui quand ('this morning he went to school, ask him when').

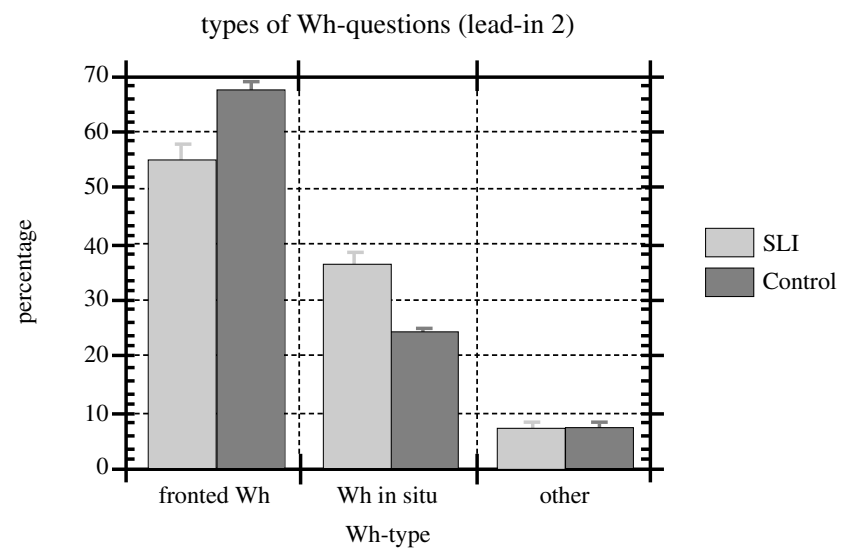

Figure 5. The production of Wh-questions by 11 SLI and 11 control children elicited with lead-in (15) as in demand lui où il habite ('ask him where he lives').

The second tendency emerging from the elicitation experiments again mirrors the spontaneous speech of these children: there is global avoidance of inversion. This emerges already from experiment 4 where spontaneous fronting of the Wh-word was never accompanied by inversion. In the repetition experiment, Experiment 5, SLIs were as good as the controls in wh-in-situ and fronted Wh without inversion but significantly worse in fronted Wh with inversion $(37.9 \%$ vs. $79.5 \%$ with 
Table 16. Correct repetition of wh-questions.

\begin{tabular}{llll}
\hline & Wh-in-situ & fronted Wh (-INV) & fronted WH (+INV) \\
\hline SLI & 90.9 & 90.9 & 37.9 \\
Control & 100 & 100 & 79.5 \\
\hline
\end{tabular}

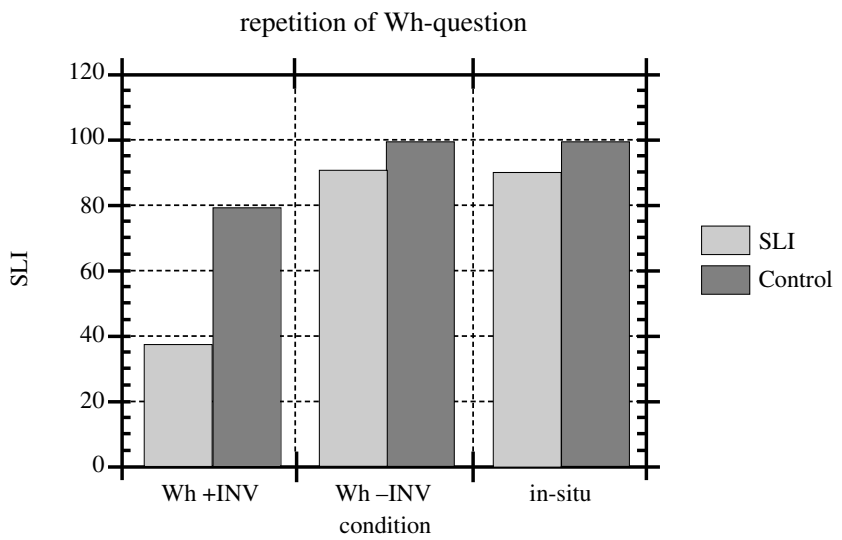

Figure 6. The percentage of correct repetition of different types of Wh-questions by 11 SLI and 11 control children.

$t(10)=-5.03, p<0.001)$. Table 16 shows the percentages. The difference between the production of wh-in-situ and fronted wh with inversion by the SLI children is also significant. Figure 6 gives an overview over the three conditions tested in the repetition task.

In Experiment 4 and 5, errors primarily occurred in the repetition of Wh-questions with inversion. Controls sometimes gave a fronted Wh-question without inversion. This error also occurred for SLI children. In addition, the SLI children sometimes dropped the subject $(27 \mathrm{a}, \mathrm{b})$ or doubled it $(28 \mathrm{a}, \mathrm{b})$, or they used an evasion strategy, as in (29). Table 17 gives an overview.

Table 17. Errors in the repetition of Wh with inversion.

\begin{tabular}{lllllll}
\hline & SVO & null subj & double subj & KESK & other & total \\
\hline SLI & 34 & 9 & 8 & 1 & 3 & 55 \\
Control & 17 & 1 & 0 & 0 & 0 & 18 \\
\hline
\end{tabular}


(27) a. Où achètes tes cahiers?

Rafaelle 5.4

where buy your note books

'Where do you buy your note books ?'

b. Où es parti en vacances?

Didier 5.11

where is gone for vacation

'Where did he go for vacation?'

(28) a. Quand tu fètes tu ton anniversaire?

Martin 6.4

when you celebrate you your birthday

'When do you celebrate your birthday?'

b. Comment tu as tu fait ce dessin?

Noelle 7.11

How you have you done this drawing

'How did you make this drawing?'

(29) Quelle chaussure pour mettre pour courir?

Noa 9.4

Which shoe for put for run

'Which shoes do you put on for running?'

Note that subject drop does not really seem to be an option for the controls, whereas the SLI children frequently produce this error. We find the results from spontaneous production corroborated again, even with respect to subject drop in fronted Wh. Moreover, the three children who produced null subjects in all question types in their spontaneous production turn out to have significantly more difficulties than the mean in repeating fronted Wh with inversion. Aurélie, has $12.5 \%$, Martin and Rafaelle $16.6 \%$ correct repetitions of the items involving a fronted Wh with inversion. Their most frequent error is the omission of the subject (10\%) or doubling of the subject, which was not found in the controls. Martin also repeated fronted Wh-questions without inversion less reliably than the other SLI children. Corentin, one of the children who avoids questions altogether, had special difficulties with these tasks. He could repeat inverted Wh only $12.5 \%$ correctly, he was worse than the other SLI children when repeating fronted Wh without inversion, and he transformed all the KESK forms into in-situ questions with quoi. He showed the same difficulties in yes-no questions, where he did not produce one correct inverted structure, neither in the repetition nor in the $a$-t-il ('has he') condition.

In sum, the elicitation experiments showed clearly that SLI children have a greater tendency to use in-situ than normal children and that they avoid inversion. It was shown that typically developing children even if avoiding them are capable of producing inversion structures in certain tasks, whereas SLI children produce significantly less inverted structures in the same tasks. 


\section{Discussion and Conclusion}

\subsection{Typically developing children}

The data from spontaneous speech and from the elicitation experiment indicate that children have difficulties with complex structures and try to avoid them by using less complex structures that allow the same interpretation. The data on infinitive and null subject use in questions can be easily explained by a truncation approach, whereas I have pointed out certain difficulties for a UCC-based account. In the following I will therefore develop a proposal for the syntax of early questions based on the assumption of the truncation option as a fundamental option in early syntax and combine this with the idea that French children, especially SLI children, will prefer (and overuse) the Agree option over internal Merge (in the terms of Chomsky (1998)).

The proposal intends to account for 3 tendencies. The first tendency concerns null subjects. In the speech of these three normal children, they do not occur in fronted Wh but they do occur in in-situ questions. The second tendency concerns the development of null subject use. The third tendency I aim to account for is that null subjects systematically occur in (fronted) pourquoi- questions.

On the theoretical side, I assume a left periphery with at least two phrases involved for question formation, the Interrogative Phrase (IntP) and the traditional Wh-phrase. Rizzi (1999) derives the existence of these two positions from data on the distribution of Italian se ('if') in embedded interrogatives. The IntP, for which there is no a priori evidence in root questions, turns out to be the natural position in which Italian perché ('why') is first merged (or base-inserted in the older terminology). Rizzi (1999) gives the following main arguments for this analysis. Contrary to other question words such as che cosa ('what'), dove ('where') and come ('how'), which require inversion, perché ('why') does not allow it. Moreover, perché ('why') can occur together with a focused constituent in Italian. In an articulated CP structure as suggested by Rizzi (1997) and given that the traditional Wh-phrase has been assimilated to the Focus Phrase, this provides evidence that perché ('why') is indeed in a position higher than the Whphrase.

These arguments also apply to French pourquoi ('why'). The first indication that it is first merged (base inserted) in a Wh-related position not in a lower adverbial position, is the fact that pourquoi ('why') does not occur in-situ as the contrast in $(30 \mathrm{a}, \mathrm{b})$ shows. This position is not the usual Wh-position, as the next two arguments show. Like its Italian counterpart, pourquoi ('why') does not occur with inversion, at least it is decidedly odd in the construction known as Stylistic Inversion, see (31a,b). (32a,b) show that pourquoi ('why') is not totally incompatible with a focused constituent, whereas other questions words are.

(30) a. Ou est-ce que tu vas? where is it that you go?

'Where are you going?' 
b. *Pourquoi est-ce que tu pars? why is it that you leave 'Why are you leaving?'

(31) a. Comment a parlé Jean? how has spoken Jean 'How did John speak?'

b. *?Pourquoi a parlé Jean?23 why has spoken John 'Why did John speak?'

(32) a. *Quand MON LIVRE t' a donné à Jean, pas le tien? when my book you have given to John, not yours '*When did you give MY BOOK to John, not yours'

b. ?Pourquoi MON LIVRE t' a donné a Jean, pas le tien why my book you have given to John, not yours 'Why did you give MY BOOK to John, not yours?'24

For these reasons I assume that pourquoi ('why') occupies a specific position high in the clause. The analysis can also be applied to English why. Shlonsky (p.c.) proposes that why is not first merged (base inserted) in the IntP but short moved from a position to the left of the WhPhrase. The arguments derive from the examples $(33 a, b)$ and the two readings of (34).

(33) a. I don't know when to leave.

b. *I don't know why to leave

(34) Why did John finally decide to leave?

The question now is: How can why be interpreted as having scope over the lower clause in (34), if it cannot appear overtly in an indirect infinitival question? Shlonsky's answer is that why is first merged in a high position (higher than negation), and subsequently raises to a Wh-licensing position, which is unavailable in infinitives. In this position why has scope over the lower clause.

Putting these proposals together, I assume a ReasonP, where why is first merged (base generated) to the left of the $\mathrm{WhP}$ and lower than the Interrogative Phrase.

23. The example and judgment is taken from Rizzi (1990:48)

24. (32b) is odd and Pourquoi t'as donné MON LIVRE à Jean, pas le tien ('why did you give my book to John, not yours') is much better. Note, however, that leaving the focused argument in a lower position, does not improve (32a): * quand t'as donné MON LIVRE à Jean, pas le tien (*when did you give my book to John, not yours'), just as it does not improve the English translation. Clearly, pourquoi ('why') is compatible with focused constituents, whereas other question elements are not. 
This gives the structure in (35). It is further assumed that adult fronted Wh-questions are derived by movement. In-situ questions could be derived parallel to fronted-Wh by internal merge of the Wh-operator after spell-out, or by first merging a question operator in the specifier position of the WhP, which then binds a choice function. In both analyses, an adult in-situ question will have a question operator in the specifier of WhP. This is the important fact for my analysis of child questions, which - departing from Hamann (2000) - remains neutral with respect to the nature of this operator.
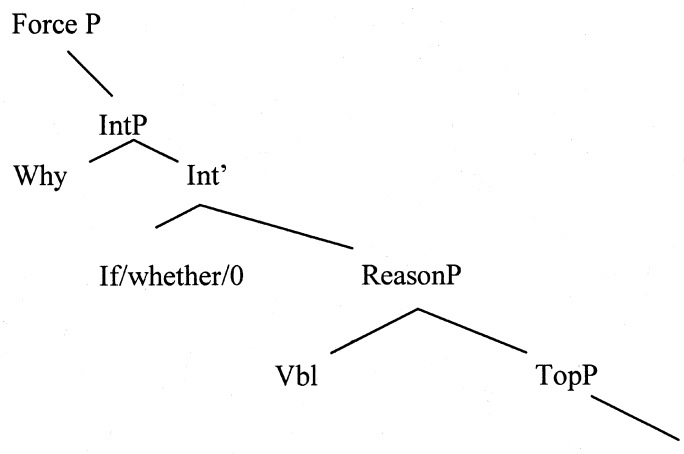

Foc/WhP

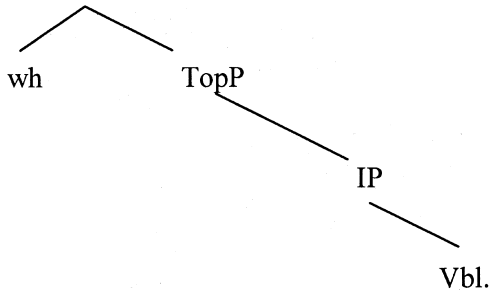

For early child grammar it is likely that, in accordance with economy, children truncate as much as possible. Following Rizzi (1994), it is assumed that 0-subjects are restricted to the specifier of the root. If in fronted Wh-questions, truncation operates down to the WhP, then null subjects are excluded. For in-situ questions truncation also operates down to the WhP. It is not likely that the WhP is truncated because the child interprets such constructions as questions. So there must be a question element (Q-element) in a high projection. The assumption I make is that children do not have an operator analysis for Wh-in-situ in the beginning, but assume a Q-head as a minimal requirement for interpretation. By the complexity metric, this allows a minimal derivation where the Q-head enters into an Agree relation with the Wh-word in-situ. In this configuration the specifier of the WhP is not filled, which would allow null subjects. 
If we further assume Shlonsky's analysis of why and pourquoi ('why') we can easily explain the occurrence of null subjects in this question type: the child does not short-move pourquoi ('why'), but assumes an in-situ analysis. Because of the high position of the ReasonP, this in-situ analysis looks like an adult pourquoi ('why') question. As long as this in-situ analysis exists, null subjects are possible in pourquoi ('why') questions following the same logic as outlined for other in-situ questions with the difference that the child has truncated the ForceP and nothing more. The similarity of pourquoi ('why') and in-situ questions is shown in (36a,b).

(36) a. NS Q-head why

null-subject in a why-question

b.

NS Q-head V wh null subject in an in-situ question

What has to be considered, however, is the question how children grow out of this option. Looking at Augustin, the child who was recorded up to almost age $2 ; 10$, we observe that the null subjects in in-situ questions vanish at approximately the time he starts using fronted Wh more systematically. This could be the time when he recognizes that in-situ questions and fronted Wh-questions are of the same semantic type. The principle of Categorial Uniformity should then force him to abandon the Q-head analysis and assume an operator in the specifier of the Whphrase for both question types. ${ }^{25}$ Now the specifier position is occupied and null subjects are no longer possible.

Unfortunately, the same scenario does not apply to the other two children whose use of fronted Wh remains rare. It seems plausible, however, that growing awareness of fronted Wh and inversion structures in the input triggers the operator analysis. Note that it has been argued on independent grounds that the operator-variable analysis of questions is not available to young children (see Roeper and deVilliers (1991)). Whereas English children acquire the variable analysis only around the age of 4 years, an exploratory study shows that French children use it earlier. ${ }^{26}$ What exactly it is that triggers the reanalysis - an accumulation of input, more systematic production of fronted Wh-questions, first production of inversion or the acquisition of the operator-variable analysis - needs more data, a careful analysis of the input and experiments on production and comprehension.

As to SLI children, we saw that they avoid questions, prefer in-situ constructions, avoid inversion and allow null subjects in in-situ questions as well as in fronted Wh. These results, particularly the results on Wh-elicitation shown in figure 4, are compatible with the RDDR. In general, however, these children's grammar does not seem to be so very different from that of the younger, normal children. The same conclusion is reached by Jakubowicz (2004), who claims that SLI children have

25. See Baranzini for a similar suggestion. Baranzini does not use a Split CP, she simply states that in fronted Wh questions the CP must be activated. In-situ questions are quickly recognized as of the same semantic type as fronted $\mathrm{Wh}$, so that $\mathrm{CP}$ is activated from then on. Declaratives are the last to be analyzed as CPs.

26. The work of Daméry, Dussauze and Schelling (2000) showed that typical French children have over $80 \%$ variable readings around the age of four. 
difficulty with computational complexity (i.e. inversion) but nevertheless have a movement analysis for Wh-questions.

There must be a subtle difference in the grammar of normal children and of children with SLI, however, to explain the occurrence of null subjects in fronted Wh-questions and some of the characteristic errors in the elicitation tasks. Neither the RDDR nor the HCC explains the fine-grained syntactic patterns described above.

A possible explanation could be that SLI children try to transfer the in-situ analysis described above to all questions. If it is assumed that SLI children are even more economical than normal children because they are more limited in working memory or processing capacity, it can be supposed that they prefer to establish an Agree-Relation between two elements over a derivation using internal merge (the traditional movement). Therefore it is possible that they extend the «Wh-head AGREE Wh-word» analysis to fronted Wh questions. This implies that they misanalyze the Wh-operator and merge it in head position. The evidence for such a misanalysis is derived from the observations that there is no spontaneous inversion, that there are disproportionate difficulties with inversion in the elicitation tasks. This indicates that the head position is occupied and cannot receive the auxiliary or verb. Especially the a-t-il il a un chapeau ('has he he has a hat') error suggests that the head position is not available and is occupied by whatever is analyzed as the question element by the child, by $a-t-i l$ ('has he') in this particular case. Such an analysis would allow the use of null subjects in fronted Wh as observed in spontaneous but also in elicited production.

It is possible that some children never grow out of this analysis which together with increasing exposure to inversion structures leads to insecurity and so the avoidance of questions, at least of fronted Wh questions, as far as possible. The other children, who are all in the younger group, may follow the path of their normal peers and eventually arrive at an operator analysis, only that they need more evidence and thus more time.

The results presented here for typically developing and children with SLI, especially the patterns of null subject occurrence in spontaneous speech and the error types found in the elicited production of questions, could be accounted for with a few economy oriented assumptions. The principle of Structural Economy introduced by Rizzi has been used as the underlying principle. In addition, it has been assumed that children find it more costly to merge elements internally (move) than to establish a long distance Agree-relation. The last assumption was that it is even more costly to entertain two different analyses for one semantic type, as suggested by Rizzi's principle of Categorial Uniformity. Because these simple assumptions are basic extensions of recent suggestions (Rizzi (2000), Jakubowicz (2004)) and allow a natural explanation of the data, they attain a certain degree of plausibility. More data might decide whether the assumptions I make about SLI could even be extended to the earliest stages of normal question development confirming the parallel development or whether questions are indeed an area where qualitative differences in syntactic phenomena point to an underlying difference in normal and impaired grammars. 


\section{References}

Baker, C.L. (1970). «Notes on the description of English questions. The role of an abstract question morpheme.» Foundations of Language 6: 107-219.

Baranzini, Lara (2003). Le sujet nul, les infinitives racine et les questions Wh dans la grammaire des enfants normaux et des enfants SLI francophones. University of Geneva, DEA-thesis.

Bloom, Paul (1990). «Subjectless sentences in child language». Linguistic Inquiry 21:491-504.

Boskovic, Zeljko (2000). «Sometimes in SpecCP, sometimes in-situ». In: Martin, R.; Michael, D.; Uriagereka, J. (eds.). Step by Step. Cambridge, Mass.: MIT Press, pp. 53-88.

Bromberg, H.; Wexler, Ken (1995). «Null subjects in child Wh-questions». MIT Working Papers in Linguistics 26: 221-247.

Cardinaletti, Anna; Starke, Michal (1994). «The typology of structural deficiency». University of Geneva, unpublished manuscript.

Chang, Lisa (1977). Wh-in-situ Phenomena in French. University of British Columbia, master's thesis.

Cheng, Lisa; Rooryck, Johan (2000). «Licensing Wh-in-situ». Syntax 3,1:1-19..

Chomsky, Noam (1976). «Conditions on rules of grammar». Linguistic Analysis, vol.2; no.4. Reprinted in Chomsky, Noam (1977). Essays on Form and Interpretation. Amsterdam: North Holland.

- (1995). The Minimalist Program. Cambridge, Mass.: MIT Press.

- (1999). «Derivation by phase». MIT Occasional Paper in Linguistics 20, Cambridge, Mass.

Clahsen, Harald; Kursawe, Claudia; Penke, Martina (1996). «Introducing CP: Whquestions and subordinate clauses in German child language». Essex Research Reports in Linguistics 7:1-28.

Clark, Robin; Roberts, Ian (1993). «A computational model of language learnability and language change». Linguistic Inquiry 24: 299-345.

Crain, Stephen; Thornton, Rosalind (1998). Investigations in Universal Grammar. Cambridge, Mass.:MIT Press.

Crisma, Paola (1992). «On the acquisition of Wh in French». Geneva Generative Papers 0 (1-2): 155-122.

Cronel-Ohayon, Stephany (2004). Etude longitudinal d'une population d'enfants dysphasiques. University of Geneva, doctoral dissertation.

Daméry, L.; Dussauze, M.; Schelling, R. (2000) «La compréhension des questions Wh chez des enfants dysphasiques francophones». Recherche de 2ème cycle, Department of Psychology, University of Geneva.

Friedemann, Marc-Ariel (1992). «The underlying position of external arguments in French». Geneva Generative Papers 0 (1-2): 123-144.

- (2000). «Early French Postverbal Subjects». In: Friedemann, Marc-Ariel; Rizzi, Luigi (eds.). The Acquisition of Syntax. London: Longman, pp. 63-83.

Guasti, Maria-Teresa (2000). «An excursion into interrogatives in early English and Italian». In: Friedemann, Marc-Ariel; Rizzi, Luigi (eds.). The Acquisition of Syntax. London: Longman, pp. 105-128. 
Guasti, Maria-Teresa; Rizzi, Luigi (1996). «Null Aux and the acquisition of residual V2». In Stringfellow, Andy; Cahana-Amitay, Dalia; Hughes, Elizabeth; Zukowski, Andrea (eds.). Proceedings of the $20^{\text {th }}$ Annual Boston University Conference on Language Development. Somerville, Mass.: Cascadilla Press, pp. 284-295.

Hamann, Cornelia (1998) «The acquisition of Wh- revisited». Paper presented at the Liverpool Questions Conference, november 1998.

- (2000). «The acquisition of constituent questions and the requirements of interpretation». In: Friedemann, Marc-Ariel; Rizzi, Luigi (eds.). The Acquisition of Syntax. London: Longman, pp. 170-201.

- (2000b). «Negation, infinitives and heads». In: Powers, Susan; Hamann, Cornelia (eds.). The Acquisition of Scrambling and Cliticization. Dordrecht: Kluwer, pp. 423-477.

- (2002). From Syntax to Discourse. Dordrecht: Kluwer.

- (2004). «Comparing the development of the nominal and the verbal functional domain in French language impairment». In: Prévost, Philippe; Paradis, Johanne (eds.). The Acquisition of French in Different Contexts. Amsterdam: John Benjamins, pp. 109-144.

Hamann, Cornelia; Cronel-Ohayon, Stephany; Dubé, Sébastien; Frauenfelder, Ulrich; Rizzi, Luigi; Starke, Michal; Zesiger, Pascal (2003). «Aspects of grammatical development in young French children with SLI». Developmental Science 6: 151158.

Hamann, Cornelia; Penner, Zvi; Lindner, Katrin (1998). «German impaired grammar: The clause structure revisited». Sonderheft: 'Specific Language Impairment in Children.' Language Acquisition 7: 193-246.

Hamann, Cornelia; Plunkett, Kim (1998). «Subjectless sentences in child Danish». Cognition 69: 35-72.

Hamann, Cornelia; Rizzi, Luigi; Frauenfelder, Ulrich (1996). «The acquisition of subject and object clitics in French». In Clahsen, Harald (ed). Generative Perspectives on Acquisition. Amsterdam, John Benjamins, pp. 309-334.

Heim, Irene (1982). The Semantics of Definite and Indefinite Noun Phrases. Ph.D. dissertation, University of Massachusetts, Amherst. Published 1989, Garland.

Huang, C.T. James (1982). Logical Relations in Chinese and the Theory of Grammar. MIT, doctoral dissertation.

Hulk, Aafke; Zuckermann, Shalom (2000). «The interaction between input and economy: Acquiring optionality in French Wh-questions». In: Howell, S. Catherine; Fish, Sarah.A.; Keith-Lucas, Thea (eds). Proceedings of the $24^{\text {th }}$ Annual Boston University Conference on Language Development. Somerville, Mass.: Cascadilla Press, pp. 438-449.

Jakubowicz, Celia (2004). «Question formation in French SLI: Is movement costly?». Paper presented at Groningen Workshop on the L1 Acquisition of Tense, Aspect and Questions. June 11, 2004, University of Groningen.

- (2005). «The language faculty: $(\mathrm{Ab})$ normal development and interface constraints». Paper presented at GALA 2005.

Jakubowicz, Celia; Nash, Lea (2001). «Functional categories and syntactic operations in (ab)normal language acquisition». Brain and Language 77:321-339. 
Ko, Heejeong (in press). «On the structural height of reason Wh-adverbials». In Cheng, Lisa; Corver, Norbert (eds.). Wh-Movement on the Move. Cambridge, Mass.: MIT Press.

Leonard, Laurence (1998). Children with Specific Language Impairment. Cambridge, Mass.: MIT Press.

Levow, G.-A. (1995). «Tense and subject position in interrogatives and negatives in Child French: Evidence for and against truncated structures». In: Schütze, Carson; Granger, Jennifer; Broihier, Kevin (eds.). MIT Working Papers in Linguistics 26. Cambridge MA:MIT, pp. 281-304.

MacWhinney, Brian (2000). The CHILDES Database: Tools for Analyzing Talk. Mahwah, NJ: Lawrence Erlbaum Associates.

Mathieu, Eric (1998). «French Wh-in-situ and intervention effects». Paper presented at the Liverpool Questions Conference, November 1998.

Pesetsky, David (1987 ). «Wh-in-situ: Movement and unselective binding». In: Reuland, Eric; terMeulen, Alice (eds.). The Representation of (In)definites. Cambridge, Mass: MIT Press.

Philips, Colin (2003). «Syntax at age two: Cross linguistic differences». In: Schütze, Carson; Ganger, Jennifer; Boihier, Kevin (eds.). MIT Working Papers in Lingusitics 26:325-382.

Pierce, Amy (1989). On the Emergence of Syntax: a Cross-linguistic Study. MIT, doctoral dissertation.

Plunkett, Bernadette (2004). «Early peripheries in the absence of C». In: Adger, David; De Cat, Cecile; Tsoulas, George (eds.). Peripheries. Syntactic Edges and Their Effect. Dordrecht:Kluwer, pp. 383-405.

Plunkett, Bernadette; De Cat, Cécile (2001). «Root specifiers and null subjects revisited». In Do, Anna H.-J., Dominguez, Laura; Johansen, Aimee (Eds.). Proceedings of the $25^{\text {th }}$ Annual Boston University Conference on Language Development. Somerville, Mass.: Cascadilla Pres,. pp. 611-622.

Rasetti, Lucienne (1995). La distribution du sujet nul dans la grammaire enfantine du francais. University of Geneva, mémoire de licence.

- (2000). «Null subjects and root infinitives in the child grammar of French». In Friedemann, Marc-Ariel; Rizzi, Luigi (eds.). The Acquisition of Syntax. London: Longman, pp. 236-268.

- (2003). Optional Categories in early French Syntax: a developmental study of root infinitives and null arguments. University of Geneva, doctoral dissertation.

Reinhart, Tanya (1995). «Interface strategies». OTS Working Papers, University of Utrecht.

- (1997). «Quantifier scope: How labor is divided between QR and choice functions». Linguistics and Philosophy 20:335-397.

Rice; Mabel; Wexler, Ken (1995). «Extended optional infinitive (EOI) account of Specific Language Impairment». In: Stringfellow, Andy; Cahana-Amitay, Dalia; Hughes, Elizabeth; Zukowsky, Andrea (eds.). Proceedings of the $20^{\text {th }}$ Annual Boston University Conference on Language Development. Somerville, Mass.: Cascadilla Press, pp. 610-621.

Rizzi, Luigi (1990). Relativized Minimality. Cambridge, Mass.: MIT Press.

- (1991). «Residual verb second and the Wh-criterion». Technical Reports on Formal and Computational Linguistics No2, University of Geneva. Appeared also in Belletti, 
Adriana; Rizzi, Luigi (eds.). Parameters and Functional Heads. Oxford: Oxford University Press. (1996,. pp 371-393.

- (1994). «Some notes on linguistic theory and language development: the case of root infinitives». Language Acquisition 3: 371-393.

- (1995). A Note on Do-support. University of Geneva, unpublished manuscript.

- (1997). «The fine structure of the left periphery». In: Haegeman, Liliane (ed.). Elements of Grammar. A Handbook of Generative Syntax, pp. 281-337.

- (1999). «On the position "Int(errogative)" in the left periphery of the clause». University of Siena, MS.

- (2000). «Remarks on early null subjects». In: Friedemann, Marc-Ariel; Rizzi, Luigi (eds.). The Acquisition of Syntax. London: Longman, pp. 269-292.

Roeper, Tom; de Villiers, Jill (1991). «The emergence of bound variable structures». In: Maxfeld, T.; Plunkett, Bernadette (eds.). Papers on the Acquisition of Wh. University of Massachusetts Occasional Papers. Amherst, Mass.: GLSA Publication, pp. 225-65.

Roeper, Tom; Rohrbacher, Bernhard (2000). «Null subjects in early child English and the theory of economy of projection». In: Powers, Susan; Hamann, Cornelia (eds.). The Acquisition of Scrambling and Cliticization. Dordrecht: Kluwer, pp. 345-396.

Safir, Ken (1992). «Structural economy». Rutgers University, unpublished manuscript.

Schütze, Carson; Wexler, Ken (1996). «Subject case licencing and English root infinitives». In: Stringfellow, Andy; Cahana-Amitay, Dalia; Hughes, Elizabeth; Zukowsky, Andrea (eds.). Proceedings of the $20^{\text {th }}$ Annual Boston University Conference on Language Development. Somerville, Mass.: Cascadilla Press, pp. 670-681.

Shlonsky, Ur (in preparation). «On Wh and why». University of Geneva, unpublished manuscript.

Strik, Nelleke (2005). «Computational complexity and the production of long distance questions in child French». Paper Presented at GALA 2005.

Suppes, Paul; Smith, R.; Leveillé, Madeleine (1973). «The French syntax of a child's Noun Phrases». Archives de Psycholgie 42:207-269.

Thornton, Rosalind (1990). Adventures in Long-distance Moving: The Acquisition of Complex Wh-questions. University of Connecticut, doctoral dissertation.

- (2004). «Why continuity». In: Brugos, Alejna (ed.). Proceedings of the 28th Annual Boston University Conference on Language Development 28: 620-632.

Treichler, Michael (in preparation) A cross-linguistic comparison of the acquisition of why-questions by young children. Master's thesis, University of Oldenburg.

Van der Lely, Heather (1998). «SLI in children: movement, economy and deficits in the computational-syntactic system». Language Acquisition 7: 161-192.

Von Stechow, Arnim (1999). Some Remarks on Choice Functions and LF Movement. University of Tübingen, unpublished manuscript.

Wexler, Ken (1994). «Optional infinitives, head movement and the economy of derivations in child grammar». In: Hornstein, N.; Lightfoot, D. (eds.). Verb movement. Cambridge: Cambridge University Press, pp. 305-350.

- (1998). «Very Early Parameter Setting and the Unique Checking Constraint: a new explanation of the Optional Infinitive Stage». Lingua 106: 23-79.

- (2000). «Three problems in the theory of the optional infinitive stage: stage/individual predicates, eventive verbs, and finite null subjects». Proceedings of WCCFL 19: 101-114. 
- (in press). «The Unique checking constraint as the explanation of clitic omission in SLI and normal development.» In: Jakubowicz, Celia; Nash, Lea; Wexler, Ken (eds.). Essays on Syntax, Morphology and Phonology in SLI. Cambridge, Mass: MIT Press.

Wijnen, Frank (1997). «Temporal reference and eventivity in root infinitives». MIT Occasional Papers in Linguistics 12: 1-25. 